\title{
AN INTEGRATED MODEL TO STUDY THE EFFECTS OF OPERATIONAL PARAMETERS ON THE PERFORMANCE AND POLLUTANT EMISSIONS IN A UTILITY BOILER
}

\author{
Hamid Abroshan ${ }^{1, *}$
}

\begin{abstract}
A gas fired tangentially boiler was modeled under full load conditions. Furnace was simulated by CFD and then was joint with two mathematical models to calculate heat transfer in the convective section, and metal temperature of waterwall tubes. Effects of changing the combustion excess air ( 0 to $20 \%)$ and burners tilt angle $\left(-30^{\circ}\right.$ to $\left.+30^{\circ}\right)$ were studied. Results showed that the boiler efficiency is optimum if excess air $=10 \%$ and the burners have a negative angle. However, these optimum settings cannot produce a superheated and reheated steam of $538{ }^{\circ} \mathrm{C}$ which is desirable. Indeed, a zero or positive tilt angle with $10 \%$ excess air, or a negative burner angle with $15 \%$ excess air lead to highest efficiency by considering the potential of generating superheated steam of $538^{\circ} \mathrm{C}$. In addition, $\mathrm{CO}$ emission in low excess air values growths by increasing the burner tilt angle. NOx emission in low and high excess air ratios is lower at positive burner angles while a moderate excess air $(10 \%)$ needs a zero tilt angle to minimize NOx emission. Furthermore, a critical fouling thickness was computed, considering boiler's circulation ratio, in which the metal temperature of the waterwall exceeds the short overheating threshold. With a certain thickness of scale layers inside the tubes, a burner tilting equal to $0^{\circ}$ or $30^{\circ}$ postpones tube rupture. These results could be utilized by operating engineers to keep their utility boilers in the most efficient state and avoiding overheating and tube rupture.
\end{abstract}

\section{Keywords: Non-Premixed Combustion, Burner, Excess Air, Deposition, Thermal Efficiency, NOx and CO Emission}

\section{INTRODUCTION}

Boilers are one of the most important components in steam power plants from design and operation viewpoints. They are at the heart of steam stations and many other industries such as petroleum processing. This importance was the main source of a lot of attempts for modeling the utility boilers during past decades. Most of these efforts were conducted to improve the performance of boilers by optimizing their design or operating parameters. Whereas boilers consist of various complex processes (e.g. combustion, boiling, gas radiation, and turbulence flows at different parts), it is hard to bring all of them together. So research articles mostly focused on a single modeling approach which is relevant to their discussed problem. Different modeling approaches are applicable in this area, such as: CFD simulation of the furnace, CFD simulation of the convective section, and mathematical modeling of the boiler. Computational fluid dynamics gains a great attention in the boiler simulation during past decades after rising the computational abilities. They were used mostly for determining the distribution of flow and heat inside a furnace, predicting pollutant emissions, detecting malfunctions in a boiler and proposing modifications to prevent them.

\section{CFD MODELING OF BOILERS}

CFD simulations are widely used to find the flow and heat patterns inside a boiler (gas side) mainly to suggest an improvement. Utility boiler of a $120 \mathrm{MW}$ natural gas fired power plant was modeled by CFD in a 296,000 meshed domain [1]. Authors included the rear pass in their simulation and concluded that the flow in the furnace is highly swirled for the tangentially fired burners. Evaluating the heat absorption in a co-firing boiler was performed by CFD while a heavy fuel oil was replaced by a bioliquid [2] showing a reduction in heat absorption. In another article, a complete boiler was modeled by CFD whereas the convective elements were considered as porous media [3]. The

This paper was recommended for publication in revised form by Regional Editor Alibakhsh Kasaeian

${ }^{1}$ Power Generation Department, Niroo Research Institute (NRI), Tehran, Iran

${ }^{*} E$-mail address: pabroshan@gmail.com

Orcid id: 0000-0003-1914-3194

Manuscript Received 25 November 2018, Accepted 12 February 2019 
model was only poor in predicting the furnace outlet temperature. Other studies were conducted to discuss the temperature and flow fields inside a furnace to find a matched model with the real boiler for further investigations [4].

The other application of CFD in boilers is for estimating the pollutant emissions. The effectiveness of a modified over fire air technology (OFA) was studied by CFD modeling of a $600 \mathrm{MW}$ pulverized boiler [5]. They discussed the parameters influencing NOx reduction by their simulation. In another study, formation of nitric oxides was investigated in a dual fuel boiler under three different loads [6]. An integration of a staged combustion technology and OFA was also analyzed for a heavy oil fired boiler [7]. Authors claimed that $\mathrm{CO}$ was predicted well by the CFD model while NOx was overestimated slightly. Studying the NOx and CO formation by means of CFD is an accepted method which has utilized in many other researches especially to evaluate the staging and OFA [8,9]. Although CFD simulations were widely used to estimate pollutant emissions successfully, some articles stated that CFD could not be accurate enough in this area. For example, CO formation which was obtained from a CFD simulation was $2000 \%$ higher than measured values, while the furnace exit temperature and NOx formation were in good agreement with experimental data [10].

Sometimes CFD simulations have been used in detecting a malfunction in boilers. For example, CFD and metallurgical studies was combined to find the reason of tube rupture of platen radiant superheater in a utility boiler [11]. In another study [12], a tangentially fired boiler firing metallurgical gases was evaluated by means of CFD. Results showed that the non-uniform flow pattern which is a characteristic of tangentially fired boilers was the major reason for non-uniform wall temperature distribution and formation of hot spots. There are other research activities which used a CFD approach to diagnose operational problems or to suggest modifications in burners/air system configuration [6,13]. Evaluating the effectiveness of an offered modification by CFD is also common [14].

One of the most interesting boiler simulations belongs to a combination of CFD and a commercial software package to provide a more realistic model [15]. Authors used their coupled method between steam-side and gas-side to fine-tune the waterwall heat flux as an exact boundary condition for the boiler CFD model. The convective elements were also simulated as porous media. It seems that there are a few published articles with the same approach. However, in some researches, a furnace CFD model was combined with a porous media model or a 1D mathematical model of convective elements, such as [16].

Fouling in boilers has been considered in some research, too. However, most of them were concentrated on the ash deposition over the surface of tubes, not the water scale inside tubes. A method was suggested to discover the locations with highest possibility of adherence of ash particles on the waterwall in a coal fired boiler [17]. In another investigation, effect of co-firing ratio on the wall slagging and preferred deposition location was studied in a pulverized fuel boiler by numerical modeling [18]. Fouling on waterwall and convective elements was also evaluated by a thermal model which used NTU method (a mathematical model) to simply find the boiler components performance [19].

\section{MATHEMATICAL MODELING OF BOILERS}

Sometimes there is no need for such a detailed information that a CFD simulation can produce for a utility. In these situations, a mathematical model is sufficient to give necessary details with a significantly lower computational cost. They see the boiler components somehow a black box or a semi-black box comparing to CFD simulations. The main purpose of the mathematical modeling of boilers is often for forecasting the boiler outputs (e.g. steam temperature, and stack temperature) mainly at part load or transient conditions. For example, in an article a mathematical model was represented consisting of seven sub-models for different parts of a boiler (e.g. furnace, waterwall, drum, and downcomer) [20]. Dynamic response of changing the pressure set point was analyzed and the consequences of various parameters (metal temperature, circulation rate, and drum level) were discussed. Three components of a boiler (drum, superheater, and economizer) were modeled by mass and energy balance equations whereas the heat transfer from furnace to each components were considered as input [21]. They used their model to check the dynamic behavior of components by changing their heat inputs (5\% step change). Using mathematical modeling of boilers by dividing them into sub-models can be seen in many other articles: a combination of mathematical modeling and genetic algorithm to adjust the dynamic model to real plant [22], a mixed lumped and 1D model o improve predicting the dynamic responses of boiler [15], 
In some cases, a mathematical modeling was applied to analyze a single section of a boiler. For instance, waterwall of a supercritical boiler was modeled to find the mass flow rate distribution by separating it to 178 flow circuits [23]. Likewise, another research was conducted to shed light on the heating process in waterwall of a supercritical boiler by a different approach [24]. They solved 1D governing equations in transient state by knowing vertical distribution of heat flux from technical data of the boiler. Almost similar mathematical models are available in literature concentrating on waterwall in supercritical boiler at steady or transient conditions [25]. There are also research activities paying attention to convective elements of a boiler, such as [26] where a 1D model was developed for superheaters and economizers.

\section{BOILERS WITH VERTICAL BURNER TILTING}

In some utility boilers there is a possibility to angle burners (fuel and air nozzles) up or down. Vertical tilting of burners in tangentially fired boilers is not a new concept and its invention goes back to 80 years ago [27]. The main reason for introducing a tilting angle burner was for controlling the superheated (and reheated) steam temperature by changing the temperature of gas leaving the furnace. It is obvious that sloping burners up and down makes the fireball to shift up and down. Boiler operators often describe this simply as: "Negative burner angle keeps fire inside the furnace, positive burner angle send it to the superheaters". In general, tilting burners alongside attemperator spray provide an extra flexibility in controlling the temperature of superheated and reheated steam flows.

Many research papers focusing on burner tilting effects concluded an obvious result [28, 29]. Most of them used a CFD simulation to show that a positive tilting angle shifts the fire-ball to upper section of furnace and increases the superheat/reheat steam temperature. This rational shifting of fire-ball in vertical direction is also evidenced by experimental measurements [30]. NOx emission at zero, negative and positive burner angles was represented for a 67 MW boiler with OFA [31]. The results showed that no tilt situation has the minimum NOx while the negative tilting angle leads to highest NOx discharge. There are also other research articles which studied side effects of utilization of tilting burners. For instance, an increase of the deposition in the ash hopper in negative tilt angles was numerically analyzed in a pulverized coal fired boiler [32].

There are some attempts to demonstrate the effects of vertical burner tilting in utility boilers with more details. Some operational parameters (e.g. burner tilt angle and air distribution in air dampers) were considered in a CFD study of a tangentially fired pulverized coal boiler [33]. They concluded that negative or zero tilt angles lead to higher wall heat fluxes and higher variance of it over the waterwall. The peak metal temperature also occurred at zero or negative tilt angles. Upward tilting increased the NOx formation and zero tilting was the case with the lowest NOx emission. In another investigation, non-uniformity of reheated steam temperature was analyzed for different burner tilting angles [34]. CFD simulations suggested that a positive angle $\left(+11^{\circ}\right)$ causes $12{ }^{\circ} \mathrm{C}$ reduction in reheated steam temperature deviation. The authors analyzed the furnace from combustion viewpoint in another article [35]. They found that the turbulence intensity increases for higher burner angles resulting in a reduction in $\mathrm{CO}$ emission while the NOx emission rises significantly. However, the authors did not analyzed negative burner tilt angles in both of their articles.

In summary, available research papers dealing with tilting burners provide some useful information on the consequences of using them. But there are some shortages and also some unclearness about choosing a positive, negative or zero angle for burners. Most of researches focused on coal fired boilers. Articles that were reviewed here may transfer these points briefly: (1) no tilt burners has the lowest NOx emission, possibility of high metal temperature, and high heat flux to waterwall. (2) upward tilting has more NOx emission, lower reheat steam temperature deviation, higher turbulence intensity, and lower $\mathrm{CO}$ emission. (3) downward tilting results in higher heat flux to waterwall, highest NOx emission, and possibility of high metal temperature.

In this paper, a more comprehensive analysis is presented for various effects of changing burners angle on a gas fired utility boiler at full load condition. The necessity of this research arose from some key questions: (i) What is the effect of burner tilting angle on the thermal performance and pollutant emissions in a boiler? (ii) How the combustion excess air influence the boiler at different burner angles? (iii) What settings of operating parameters (burner tilt angles and excess air) may result in desirable operation? (iv) When the operator should expect a tube overheating or tube rupture? and how much the circulation ratio and scale thickness inside waterwall tubes are important? 
Answering these questions led to a study combining the CFD simulation of furnace with the mathematical modeling of convective sections and also the water/steam circuit of the evaporator. The study was concentrated on a specific utility boiler which is used in three different power plants. In total, there are 8 similar units in the country. Therefore, results of this study would be applicable for $2560 \mathrm{MW}$.

\section{METHODS}

\section{Problem Statement}

The considered issue in this study is a boiler operating in a steam power plant. The boiler consists of a furnace and a convection section (in the ceiling or rear side). The fuel mixes with the air and then burns at the furnace. This happens via 16 burners located at four levels from 8.3 meters from bottom to 14.96 meters from bottom. At each level, four tangentially burners is mounted with specific horizontal angles $\left(37^{\circ}\right.$ and $\left.46^{\circ}\right)$ to form a fireball in the middle of the furnace. The furnace dimensions are $10.458 \times 11.658 \times 39.774$ meters. The boiler generates 1056 tons superheat steam and 800 tons reheated steam per hour at full load. A platen (radiant) superheater, two convective superheaters, and two convective reheaters have the responsibility of rising the saturated steam (or low superheat reheat steam) to a temperature equal to $540{ }^{\circ} \mathrm{C}$. In addition, an economizer is located at the downstream of flue gas to increase the feedwater temperature before entering the drum.

The furnace is enclosed with series of vertical tubes named waterwall. The water enters these tubes from lower drum by help of a pump (boiler circulating pump). Thus, the outer surface of waterwall is exposed to heat (mainly radiation) while the two phase water is flowing upward in the inner side. The water starts to evaporate at waterwall.

The entire boiler is divided into three section and each section was modeled separately: furnace, convective section, and the waterwall. These models interact with each other so that some input parameters of a model obtain from the outputs of the others models. The interactions are illustrated in Figure 1 (a). The modeling starts with CFD simulation of the furnace. Then its outcomes are fed to the convective section model. The water circuit modeling is the next step in which the outcomes from both furnace and convective section models are used as inputs.

\section{Modeling the Furnace Section}

The main purpose of modeling the furnace section is to find the heat and flow fields inside the boiler. To do this, the continuity, momentum and energy equations were solved in a discretized domain by FLUENT software. In addition, combustion, radiation heat transfer, NOx formation, and $\mathrm{CO}$ formation were considered. Air and natural gas enter the furnace from sixteen tangentially burners. Each burner has two fuel gas nozzles and three air inlet channels (Figure 2). The upper and lower nozzles and channels are inclined with $5^{\circ}$ downward and upward, respectively. To achieve a more realistic inlet condition for solving the furnace domain, the flow inside a single fuel gas nozzle was simulated by CFD in the first stage. Afterwards, its outlet velocity profile was used as an inlet condition to the model of furnace.

The furnace was meshed with structured cells. A high mesh resolution was used near the furnace walls, platen superheater, and especially in the area close to burners. A case with 1.47 million elements and a Finer (2 millions) and a coarser ( 0.7 million) mesh grids were considered in order to reach the mesh independency. Some parameters such as total heat transfer to waterwall, flue gas temperature at the furnace outlet, and rate of thermal NOx did not changed significantly by increasing the mesh number more than 1 million. As a result, the case with 1 million cells is used in the current study. The furnace was modeled by some assumptions: flow is steady, furnace wall is a plain surface, and the waterwall has a constant temperature. The influence of assuming constant temperature for furnace walls will be discussed later in 3.3 . 


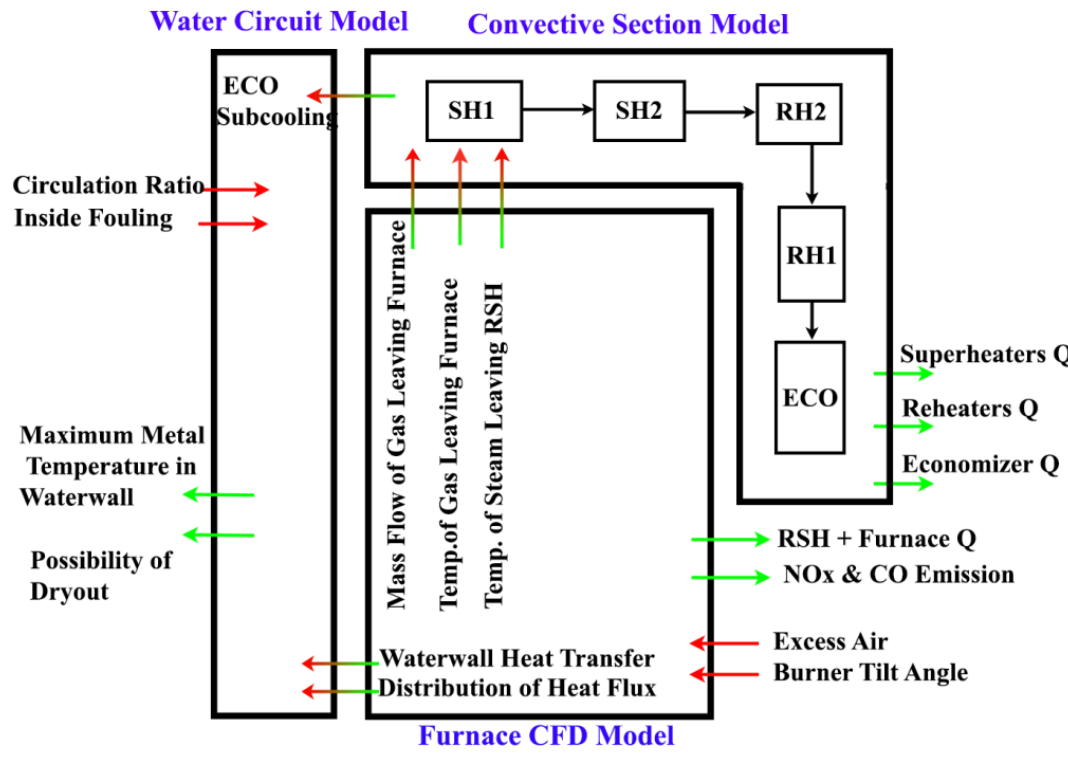

(a)

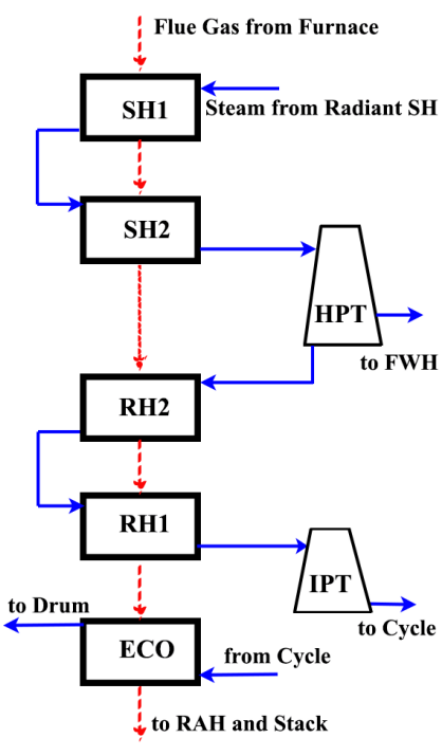

(b)

Figure 1. Overall configuration of the model, (a) the interaction between three different model and their input/output parameters, (b) flue gas and steam flow in convective section (dotted arrows are the hot gas flow)

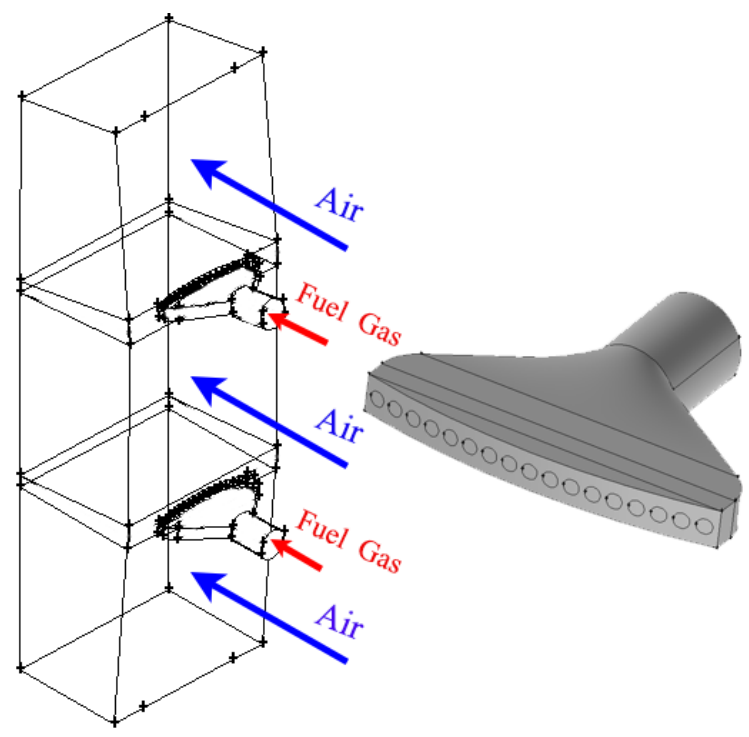

Figure 2. A single burner with two fuel gas nozzles and three air channels (left), and the fuel gas nozzle (right)

In this study, a standard k- $\varepsilon$ model was used to take into account the turbulence in the furnace. This turbulence model seems to be sufficient for modeling the flow inside an industrial furnace or burner, as it was used satisfactory in many articles $[5,6,7,10,11,14,18,33,36,37]$ and had some strengths in a comparison between turbulence models in CFD modeling of burners [38]. For combustion, the eddy dissipation model was employed. This model is appropriate for fast burning and non-premixed situations and has been utilized in some articles for modeling combustion inside furnaces [11, 12,36]. Radiation heat transfer was considered using P-1 model. This simple radiation model works good when the optical thickness in large enough as in an industrial furnace. In comparison to discrete ordinates (DO) radiation model, the P-1 was resulted nearly identical wall fluxes in modeling an oil fired boiler [7]. In addition, P-1 
radiation model was used successfully in many research articles dealing with CFD simulation of industrial boilers [3, $5,7,12,14,33]$. Thermal and prompt NOx were also included in the CFD simulation via an equilibrium model in the FLUENT software.

\section{Modeling the Convective Elements Section}

Adding the model of convective elements in the boiler (i.e. superheaters, reheaters, and economizer) gives some extra information about its performance. The boiler efficiency is one of the most important outcomes. In this article, available heat transfer correlations are used to model these convective elements. The general flow diagram of steam and hot flue gas through these heat exchangers is shown in Figure 1 (b). All of these convective elements are tube cross flow heat exchangers. Steam flows inside a bank of bare tubes (except economizer which is finned-tube) and hot gas flows over it in a cross configuration. Specifications of these elements are represented at table 1.

Table 1. Geometrical specifications of convective elements

\begin{tabular}{|l|c|c|c|c|c|}
\cline { 2 - 5 } \multicolumn{1}{c|}{} & SH1 & SH2 & RH1 & RH2 & ECO \\
\hline Tube outer diameter $(\mathrm{mm})$ & 51 & 51 & 63.5 & 57 & 51 \\
\hline Tube wall thickness $(\mathrm{mm})$ & 5.156 & 9.3 & 4.191 & 4.584 & 4.775 \\
\hline Pass number & 2 & 8 & 13 & 3 & 11 \\
\hline Tube rows in flow direction & 12 & 24 & 52 & 12 & 11 \\
\hline Tubes in transverse direction & 50 & 100 & 100 & 100 & 151 \\
\hline Tubes transverse spacing $(\mathrm{mm})$ & 228.6 & 114.3 & 114.3 & 114.3 & 76 \\
\hline Tubes longitudinal spacing $(\mathrm{mm})$ & 102 & 102 & 108 & 102 & 127 \\
\hline Tube layout & square & square & square & square & triangle \\
\hline
\end{tabular}

To find the output temperatures of each element, by knowing the input temperatures of steam and gas, a heat exchanger was divided into a few heat exchangers in series. The division performed by considering pass number of each element. For example, the second superheater ( $\mathrm{SH} 2$ ) has eight passes, so it was divided to eight cross flow heat exchangers. Outlet temperatures of steam and gas from the first division are the second division's inputs, and so on. This method gives an opportunity to obtain the gas temperature distribution inside each element.

All divisions were modeled as a single heat exchanger by NTU method. The external heat transfer coefficient can be calculated from a correlation proposed by Grismon. In this correlation, the heat transfer coefficient is a function of tube diameter, longitudinal pitch, transverse pitch, and tube layout.

$$
N u_{e x}=C R e_{\max }^{n} \operatorname{Pr}_{g a s}^{1 / 3}
$$

Where $C$ and $n$ are constants which were obtained from a table based on geometrical specifications [39], the Reynolds number computed for the minimum area between adjacent tubes. A correction factor was used which was suggested by Kays [40] for heat exchangers that have tube rows in the flow direction less than 10. The correction factor is completely important in the present study because the tube rows in flow direction for all modeled divisions are between 1 and 6 .

For heat transfer coefficient of internal flow (steam) the well known correlation of Petukhov [41] was used:

$$
\begin{gathered}
N u_{i n}=\frac{(f / 8) R e_{i n} P r_{s t}}{1.07+12.7 \sqrt{(f / 8)}\left(P r_{s t}^{2 / 3}-1\right)} \\
f=\left(1.82 \log \left(R e_{i n}\right)-1.64\right)^{-2}
\end{gathered}
$$

Another point in modeling the convective elements is about a deference between steam flow rate at superheaters and reheaters. In fact, a portion of steam flow is extracted from high pressure turbine (HPT) to increase the subcooled water to the boiler by a feedwater heater. Therefore, the mass flow rates of steam in RH1 and RH2 are 
not same as the calculated steam flow rate from CFD modeling (main steam). To take into account this flow reduction, a simple but powerful method was used to model the first stages of the intermediate pressure turbine (IPT) at off-design conditions. Mass flow coefficient which is constant at all operating points of multistage turbines is defined as below [42]:

$$
\varphi=\left(\dot{M}_{I P T} / \sqrt{\rho_{I P T} P_{I P T}}\right)_{\text {design }}=\left(\dot{M}_{I P T} / \sqrt{\rho_{I P T} P_{I P T}}\right)_{o f f-\text { design }}
$$

Based on this assumption, mass flow rate of reheated steam can be calculated by knowing the thermodynamics properties (pressure and temperature) of the final reheated steam while $\varphi$ is clear from design point. However, an iterative procedure is required to find an IPT inlet mass flow rate which fits to the thermodynamics properties of final reheated steam obtained from the convective elements model. Obviously, the difference between the mass flow rate of reheated and superheated steam equals the steam extraction from HPT. Assuming the value of steam extraction, another iterative procedure is needed to find the temperature and pressure of steam entering to reheaters. For doing this, the mass flow coefficient concept was used for HPT stage groups. Result of these two iterations, one inside the other, is the inlet and outlet temperature and pressure of reheated steam and its mass flow rate.

\section{Modeling the Water Circuit}

Modeling the water circuit inside the boiler was performed to find situations that may lead to failure in waterwall tubes. The boiler consists of 774 tubes in front, sides, and rear walls of the waterwall with an inner diameter equal to $44.5 \mathrm{~mm}$ and an outer diameter equal to $55.1 \mathrm{~mm}$. The material of all the tubes is A $210 \mathrm{~A}-1$ based on ASTM standards. This type of carbon steel has a thermal conductivity of $59.1 \mathrm{~W} / \mathrm{m} . \mathrm{K}$.

The mass flow rates of two-phase water through all vertical tubes are identical and obtained from mass flow rate of water into the boiler with considering the total number of tubes and circulation ration of evaporator. The inlet water to tubes is in saturated state. A non-constant heat flux on outer surface of the vertical tube is used. The heat flux distribution is obtained from CFD modeling of the furnace. To find the worst cases from metal temperature viewpoint, for each excess air and burner tilt angle, a vertical tube was selected in which the heat flux is highest. There is a 12.65 $\mathrm{mm}$ gap between vertical tubes which is filled with a plate connecting two adjacent tubes. Here it is assumed that the heat absorbed by these plates is transferred completely to the closest vertical tube by conduction. Then the outer surface temperature was calculated from heat transfer coefficient of the internal flow (2-phase), the metal conductivity, and tube wall thickness $(5.1 \mathrm{~mm})$.

The internal flow experiences different regimes along the vertical tube. These regimes are discussed properly in textbooks (e.g. [43]). The first regime that exists in the initial stages of the flow is a bubbly flow and the heat transfer mechanism is saturated nucleate boiling. From the bottom of tube the water temperature is equal to saturated temperature while the flow is upward. Therefore, no subcooling boiling does not exist. The essential condition for starting a nucleate boiling is exceeding the wall temperature from a threshold ("onset of nucleate boiling") as defined below $[44,45]$ in SI:

$$
T_{w_{O N B}}=T_{\text {sat. }}+0.556\left[q /\left(1082 P^{1.156}\right)\right]^{0.463 P^{0.0234}}
$$

Regarding to the range of operating parameters in the boiler, the TwONB is less than $0.3{ }^{\circ} \mathrm{C}$ larger than the saturation temperature. Thus, it is rational to assume that the saturated nucleate boiling occurs from the early stages of the vertical tubes.

For calculating the saturated nucleate boiling heat transfer, a method proposed by Gungor and Winterton was utilized [46]. In this method, based on a concept presented by Chen [47], the heat transfer coefficient is divided into two parts: a pool boiling part (micro-convective) and a forced convection part (macro-convective), as below:

$$
\propto_{n b}=E \propto_{c o n v}+S \propto_{\text {pool }}
$$


The convective heat transfer coefficient given by well-known Dittus-Boelter equation for liquid only flowing inside the tube:

$$
\propto_{c o n v}=0.023 \operatorname{Re}_{l}^{0.8} \operatorname{Pr}_{l}^{0.4} k_{l} / D_{e q}
$$

For pool boiling part, an equation from Cooper [48] was used:

$$
\propto_{\text {pool }}=55\left(P / P_{c r}\right)^{0.12}\left(-\log \left(P / P_{c r}\right)\right)^{-0.55} M W^{-0.5} q_{t u b e} 0.67
$$

Gungor and Winterton estimated the enhancement and suppression factors take into account the effect of increasing the velocity due to higher void fraction, and thinner boundary layer of superheated liquid in forced convection, respectively. These two factors for vertical tubes are computable as below:

$$
\begin{gathered}
E=1+24000 B o^{1.16}+1.37 X_{t t}^{-0.86} \\
S=\left(1+1.15 e-6 E^{2} R e_{l}^{1.17}\right)^{-1}
\end{gathered}
$$

The Martinelli parameter $(X t t)$, boiling number and $R e l$ are calculated by:

$$
\begin{gathered}
X_{t t}=((1-x) / x)^{0.9}\left(\rho_{g} / \rho_{l}\right)^{0.5}\left(\mu_{l} / \mu_{g}\right)^{0.1} \\
B o=q_{\text {tube }} /\left(G h_{f g}\right) \\
G=4 C R \dot{M}_{\text {steam }} /\left(N_{\text {tubes }} \pi D_{e q}^{2}\right) \\
R e_{l}=\rho_{l} u_{l} D_{e q} / \mu_{l} \\
u_{l}=(1-x) G / \rho_{l}
\end{gathered}
$$

After bubbly flow regime, the two phase flow of water will change to slug flow. Heat transfer in this regime was also calculated by the same method as bubbly flow. In a specific combination of operational parameters (e.g. mass flow rate, heat flux), flow regime will be changed to annular flow. In this regime, a thin layer of liquid is on the inner wall of the tubes while steam in flowing in the core region. In this article, heat transfer at annular flow regime is not calculated. The reason is that almost all the tubes at normal operating conditions in the intended boiler have not experience the annular flow. In fact, its design is so that a saturated nucleate boiling takes place all over the boiler. But, for abnormal working conditions, such as decreased circulation ratio, the point where annular flow appears was selected as an alarm for possibility of happening the dry-out. It is obvious that dry-out is completely undesirable and associates with drying the thin liquid film on the wall and a sudden increase in metal temperature. Therefore, as an alarm for occurring dry-out with a considerable safety margin, a correlation proposed by Wallis is used to predict the onset of annular flow [49]: 


$$
x_{A F}=\frac{0.6+0.4 \sqrt{g D_{e q} \rho_{l}\left(\rho_{l}-\rho_{g}\right)} / G}{0.6+\sqrt{\rho_{l} / \rho_{g}}}
$$

In this correlation, $X_{A F}$ is the vapor quality of appearing the annular flow. It is worth noting that in this section an equivalent diameter was used instead of inner diameter of tube. The $D_{e q}$ is the inner diameter considering the thin layer of fouling inside tube. In other word, the growth in flow velocity due to decreasing the cross sectional area was taken into account. The main consequences of fouling formation on tube inner wall are discussed later in this article.

\section{MODEL VALIDATION}

A complete model validation seems to be very difficult, if not impossible. The reason behind this argument is the number of parameters obtained from the model and also the complexity of measuring some parameters such as the vertical distribution of tube metal temperature or $\mathrm{CO}$ percentage at different locations of the furnace. Some of these measurements were unreachable due to lack of instruments and many others were not permitted by the power plant administrators. To compare the model outcomes with real boiler, the data recorded in log-sheets by operators was used. The most comparable parameters was sum of heat transfer to waterwall and economizer. This parameter was calculated from feed water temperature, water mass flow, and saturated temperature in drum. Numerical results are compared with measurements in table 2 for two different power plants at some points. Finding appropriate data was also a little hard because the boiler rarely operates with all 16 natural gas burners. Operators often used at least 4 burners with heavy oil fuel to ensure flame stability as they claimed. Thus there were a few usable data which presented in the below table.

Table 2. Comparing the economizer and evaporator total heat transfer obtained from model with experimental data

\begin{tabular}{|l|l|l|l|l|}
\hline $\begin{array}{l}\text { Excess air } \\
(\%)\end{array}$ & $\begin{array}{l}\text { Burner tilt } \\
\text { angle }\left({ }^{\circ}\right)\end{array}$ & $\begin{array}{l}\text { Measured } \\
\text { value }(\mathrm{kW})\end{array}$ & $\begin{array}{l}\text { Predicted } \\
\text { value }(\mathrm{kW})\end{array}$ & $\begin{array}{l}\text { Difference } \\
(\%)\end{array}$ \\
\hline \multicolumn{5}{|c|}{ Power plant NO.1 } \\
\hline 4.46 & -5 & 348587 & 351873 & +0.94 \\
\hline 4 & -9 & 349819 & 356386 & +1.88 \\
\hline 9.7 & -10 & 363012 & 361504 & -0.54 \\
\hline 10 & 15 & 364533 & 368610 & +1.12 \\
\hline \multicolumn{5}{|c|}{ Power plant NO.2 } \\
\hline 20.8 & -10 & 377402 & 338176 & -10.4 \\
\hline 18.47 & 0 & 410170 & 336000 & -18.1 \\
\hline 14.1 & 10 & 339412 & 339455 & +0.01 \\
\hline
\end{tabular}

Table 2 indicates that the developed model was completely in good agreement with measurements in power plant NO.1. However, the results are not satisfactory in power plant NO. 2, especially at two operating point with high excess air. Power plant NO. 2 is an old unit with poor operation conditions which could not reach more than its $90 \%$ load. So it is more reasonable to accept the good agreement between numerical analysis and measured values at power plant NO. 1.

In addition, $\mathrm{NOx}$ and $\mathrm{CO}$ were measured at the economizer outlet in power plant NO. 2. The measured value was $120 \mathrm{ppm}$ or NOx while the model results in NOx equal to 121 at the same conditions (excess air $=1.78 \%$ and tilt angle $=0^{\circ}$ ). Nevertheless, the $\mathrm{CO}$ was $6932 \mathrm{ppm}$ from measurement and $502 \mathrm{ppm}$ from calculations. In general, even if the model cannot predict the magnitude of some parameters good enough, it would be useful in qualitative comparison of changing various operating parameters. 


\section{RESULTS AND DISCUSSION}

\section{Furnace Section}

The CFD model described in section 2.2 was used to simulate the combustion, heat transfer, gas flow, $\mathrm{CO}$ and NOx formation for various excess air and burner tilt angles. In total, 25 simulations were implemented for five different excess air and 5 different tilt angles. The results were used to interpret thermal behavior of furnace and boiler.

Saturated steam generation is the main objective in the evaporating section of a utility boiler. So it is important to know how does excess air and burner angle affect the amount of generated steam (Figure 3). For all burner angles, the maximum heat transfer to waterwall takes place at ExAir $=5 \%$. To be more accurate, the highest thermal energy absorption by evaporator is within an excess air between $5 \%$ and $10 \%$. The reason is clear. At lower excess air ratios, fuel rich combustion occur. In these cases, some portion of $\mathrm{CH}_{4}$ remains unburned at the furnace outlet. Therefore, fuel cannot deliver its full heating potential to the evaporator. On the other hand, at higher excess air values, fuel burns entirely but existence of extra air results in cooling the combustion products. Thus evaporator absorbs less heat from the combustion. In an excess air between $5 \%$ and $10 \%$, fuel gas burns completely while there is minimum surplus air and minimum unnecessary cooling. Hence, in this optimum excess air value, maximum heat will be transferred to the evaporator.

Effect of burner tilting angle on the heat transfer to the waterwall was expected, too. In fact, one of the most important duties of changing burner tilt angle is for adjusting heat absorption by evaporator. At negative tilt angles, where burners are inclined downward, fireball moves to lower elevations. It means that high temperature gases are located at lower zones of the furnace and they have more residence time to give their energies to the waterwall. For this reason, more heat will be transferred to waterwall by radiation and convection mechanisms. In addition, turbulent rate of reaction is $45 \%$ and $65 \%$ higher for tilt $=-30^{\circ}$ comparing to tilt $=0^{\circ}$ at constant excess air (two values are related to the first and second reactions in the CFD simulation). In other words, negative tilt angles boost the heat absorption in evaporator by increasing turbulence and residence time of hot gases.

As it is obvious in Figure 3, positive tilt angles have a little difference with the no tilt angle case, although the difference is not negligible. The highest gap between tilt $=0^{\circ}$ and tilt $=+30^{\circ}$ is $10 \mathrm{MW}$, whereas in tilt $=-30^{\circ}$ the waterwall heat absorption is $22 \mathrm{MW}$ higher than tilt $=0^{\circ}$ case. The other point in Figure 3 is that the two negative tilt cases $\left(-15^{\circ}\right.$ and $-30^{\circ}$ ) results approximately in the same heat transfer to the evaporator. Even, more heat is absorbed at tilt $=-15^{\circ}$ in lower excess air values. It requires a deeper insight into the furnace to find why tilt $=-15^{\circ}$ leads to higher heat transfer to the waterwall at low excess air comparing to tilt $=-30^{\circ}$.

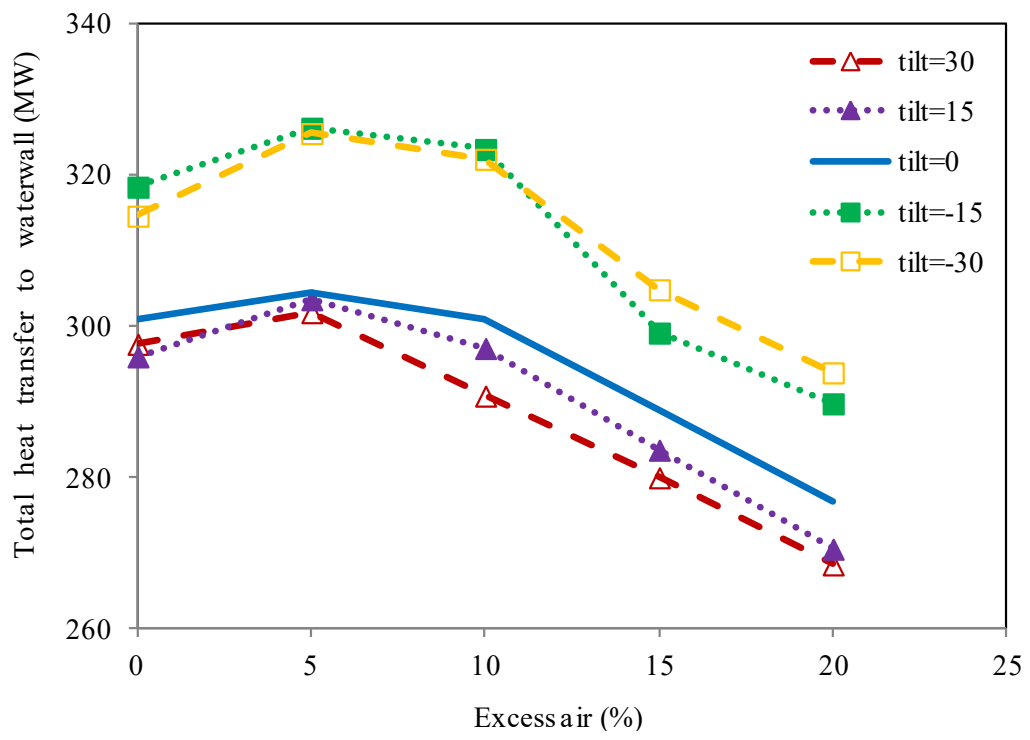

Figure 3. Total heat transfer to evaporating section vs. combustion excess air, for different tilt angles 
For better understanding of the tilt angle effects and to find an explanation for higher heat transfer rate in tilt=$15^{\circ}$ comparing to tilt $=-30^{\circ}$, it is useful to take a look at vertical distribution of heat transfer to the waterwall (Figure 4). At tilt $=0^{\circ}$, as the base case, radiant heat transfer to waterwall starts to rise at a height equal to $4 \mathrm{~m}$ while the maximum occurs at an elevation about $5 \mathrm{~m}$ above the burner zone. At higher tilt angles, heat transfer starts significantly later. This is mainly due to movement of fireball to higher elevation. It is also notable that the heat transfer rate is almost lower at all heights in positive tilt angles comparing with zero tilt angle. This is for their poor and even incomplete combustion.

Situation becomes totally different for negative burner angles. In these cases, the heat transfer to waterwall starts to rise at the bottom of the furnace. The reason is shifting the fireball to lower parts. Comparing to tilt $=0^{\circ}$, negative tilt angles have a lower maximum radiant heat transfer to waterwall. However, they have fireballs which cover a bigger portion of the furnace. In other words, heat transfer to waterwall is quite high in the most parts of furnace, and especially in the lower section (i.e. up to $16 \mathrm{~m}$ which is a little higher than burner zone). Although tilt $=0^{\circ}$ has a higher peak in heat transfer to waterwall, its vertical distribution is more concentrated. Therefore, it has lower total heat transfer to waterwall as shown in Figure 3.

The other point in Figure 4 is the difference between two negative tilting angles. They are almost identical in the heat transfer pattern above burners zone (curve of tilt $=-15^{\circ}$ is a little higher). In the burners zone, tilt $=-30^{\circ}$ has a higher heat transfer but at lower parts the situation become reversed. In fact, the heat transfer to waterwall is approximately $10 \%$ higher below the burners zone for tilt $=-15^{\circ}$. The reason behind this behavior comes from higher rate of reaction in tilt $=-30^{\circ}$ (Table 1). The turbulent rate of reaction is $40 \%$ higher in the case with tilt $=-30^{\circ}$ comparing to tilt $=-15^{\circ}$. This leads to a better combustion in the burners zone. But at tilt $=-15^{\circ}$, combustion becomes extended to lower parts of the furnace to be completed. This will be discussed later in details. Therefore, a higher gas temperature and a better radiant heat transfer to lower section of furnace is expected in tilt $=-15^{\circ}$. This is the main reason for higher total heat transfer to waterwall at tilt $=-15^{\circ}$ than tilt $=-30^{\circ}$, as was discussed for Figure 3 .

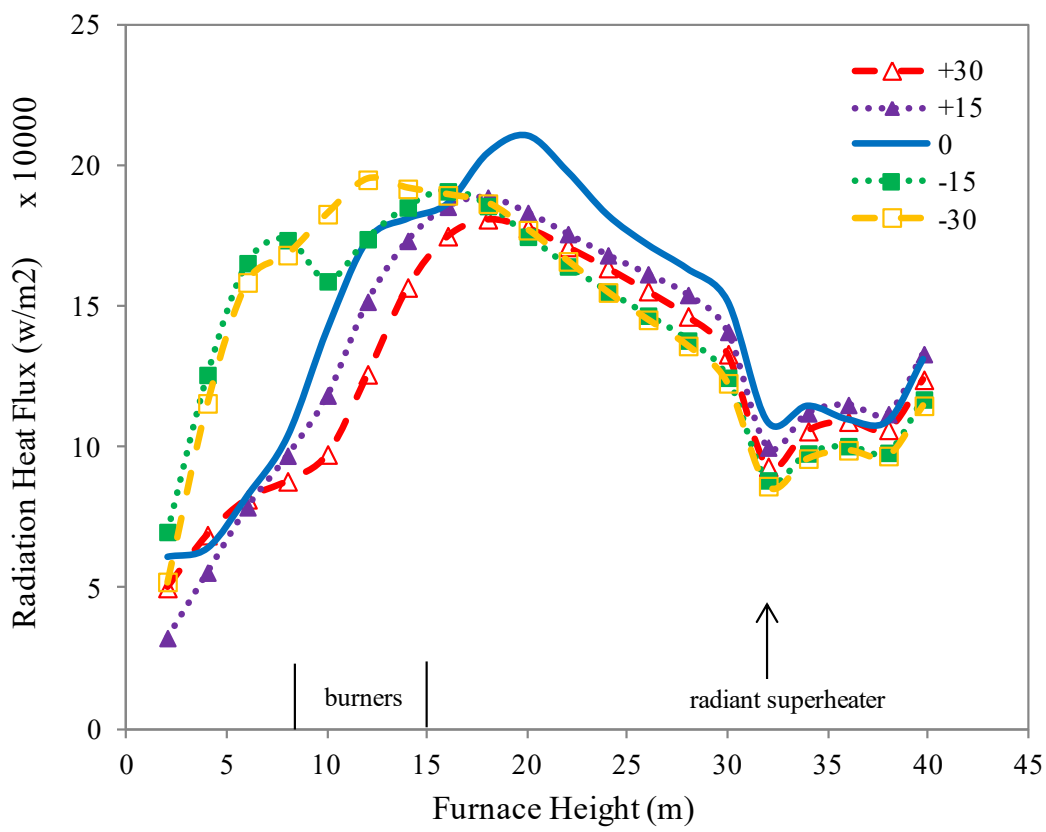

Figure 4. Vertical distribution of mean radiation heat flux in furnace

It is shown in table. 3 that turbulent rate of reaction increases when burners are inclined downward. Positive and zero tilt angles have almost similar reaction rates. This parameter becomes a little higher for tilt $=-15^{\circ}$. In tilt $=-30^{\circ}$, the turbulence rate of reaction increases significantly.

Because of incomplete combustion in some regions of the furnace, formation of carbon monoxide is unavoidable. However, the produced $\mathrm{CO}$ will converts to $\mathrm{CO}_{2}$ at its remaining path to the furnace outlet in the presence 
of plenty of oxygen. On the other hand, while the combustion takes place with a low portion of the excess air (i.e. 0 or $5 \%$ ), partial oxidation of methane will not be completed. So the CFD results showed existence of CO at the furnace outlet in lower excess airs. With an excess air equal to $5 \%, 0.03 \% \mathrm{CO}$ is obtained at the furnace exit. Although this value seems negligible, it is an indicator for an incomplete and poor combustion and waste of energy. Existence of carbon monoxide at low excess airs is more notable for positive burner tilt angles. It is mainly because of shorter residence time of gas fuel and oxygen while the burners have positive angle.

Table 3. Maximum turbulent rate of reaction for different tilt angles (at excess air $=10 \%$ )

\begin{tabular}{|l|l|}
\hline tilt angle $\left(^{\circ}\right)$ & $\begin{array}{l}\text { turbulent rate of reaction } \\
\left(\mathrm{kgmol} / \mathrm{m}^{3} . \mathrm{s}\right)\end{array}$ \\
\hline-30 & 0.407 \\
\hline-15 & 0.291 \\
\hline 0 & 0.267 \\
\hline+15 & 0.271 \\
\hline+30 & 0.276 \\
\hline
\end{tabular}

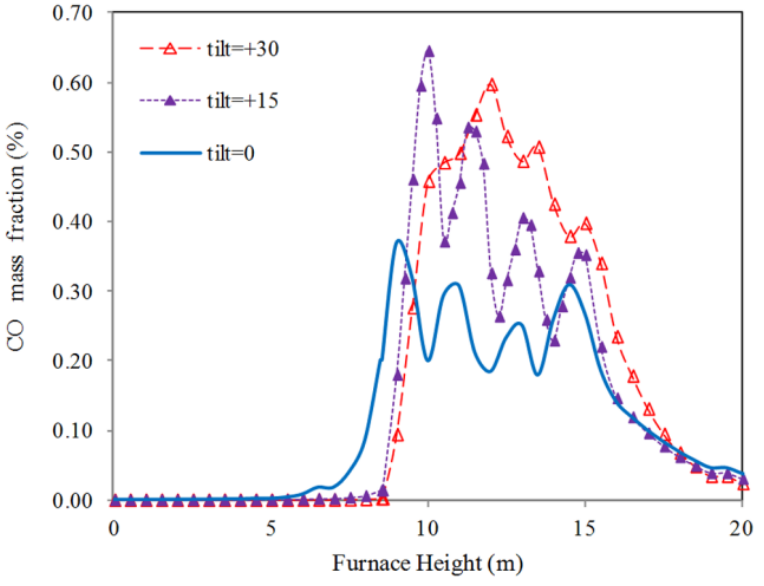

(a)

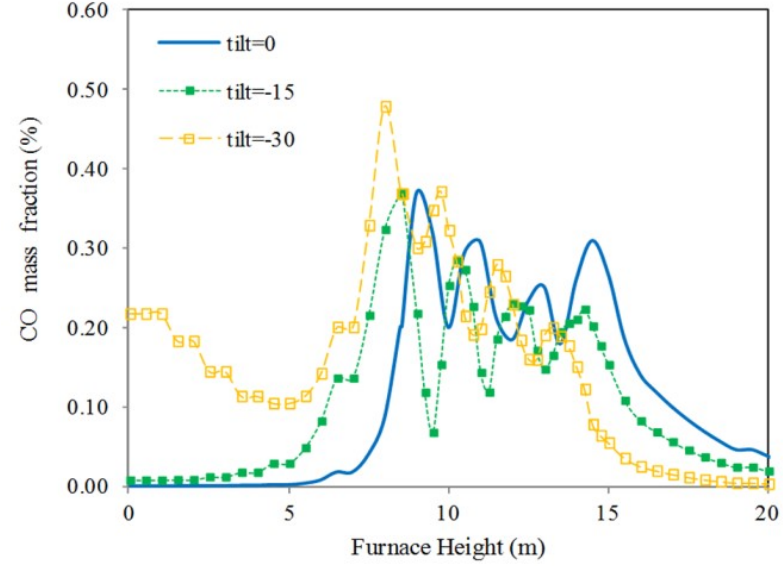

(b)

Figure 5. Vertical distribution of mass averaged values of $\mathrm{CO}$ (at excess air=10\%), (a) positive tilt angles, (b) negative tilt angles

For providing more details, vertical distribution of $\mathrm{CO}$ at various tilt angles are illustrated in Figure 5 while the excess air is equal to $10 \%$. This figure covers a range between furnace bottom and height of 20 meters where the values of $\mathrm{CO}$ are negligible. The wavy pattern of these curves is for higher $\mathrm{CO}$ concentration near burner levels due to fuel-rich regions. It is the reason why all the curves have four peaks (equal to 4 levels of burners) in Figure 5. Another point in Figure 5(b) is about extending the combustion to lower parts of the furnace in negative burner angles, as discussed in descriptions of Figure 4. Here, it is more obvious that combustion occurs at furnace bottom when tilt angle is negative. But the main difference between tilt angles of $-30^{\circ}$ and $-15^{\circ}$ lies in the level of combustion completeness in lower parts of the furnace. In fact, an incomplete combustion in the furnace bottom for tilt $=-30^{\circ}$ leads to a smaller heat transfer to waterwall surface comparing to the case with tilt $=-15^{\circ}$. Thus, as illustrated in Figure 3 , total heat transfer to the waterwall is slightly higher at tilt $=-15^{\circ}$ in lower excess air ratios. For higher excess air ratios (i.e. $15 \%$ and 20\%), combustion incompleteness in lower section of the furnace diminish due to higher availability of oxygen.

The other important aspect of combustion in the furnace is NOx formation. The results of CFD modeling are shown in Figure 6. For all burner tilt angles, a well-known behavior is visible. NOx formation in a low excess air is small and then it grows by increasing the excess air ratio. This behavior is due to larger amount of oxygen and higher 
peak temperature of flame. If the excess air rises further, the cooling effect of additional air on the gas temperature leads to lower NOx formation. In fact, a combination of oxygen and gas temperature makes this ascending-descending pattern (as seen in Figure 6). It is worth noting that thermal NOx is the dominate form of NOx in this natural gas fired boiler.

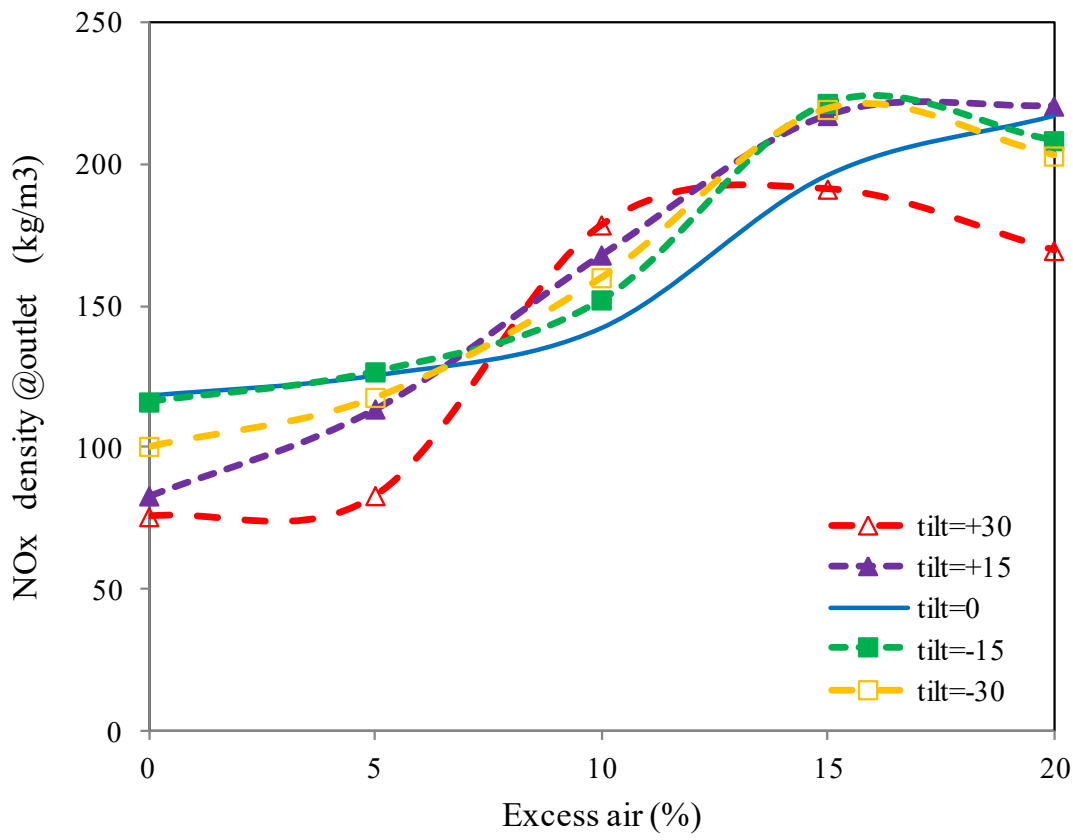

Figure 6. NOx at the outlet of furnace for different burner tilt angles and combustion excess air ratios

But the effect of burner tilt is a little more complex. As it was mentioned in the introduction, horizontal burners are suggested to produce less NOx. However, this suggestion seems to be dependent to excess air values. In low excess air ratios (i.e. $0 \%$ and $5 \%$ ), positive tilt angles generate less thermal NOx due to their lower peak temperature. The case with zero tilt angle has the highest NOx at the furnace outlet for its local peak in temperature, as was illustrated in Figure 4. By increasing the excess air, the situation becomes completely reversed. At an excess air equal to $10 \%$, oxygen becomes more available at regions of the furnace that have higher temperature. This is more severe for positive tilt angles leading to higher NOx emission. Further increasing the excess air results in a drop in NOx formation because of the cooling effect on the hot gases. The reduction starts at lower excess air ratio for tilt $=+30^{\circ}$ because the cooling effect appears earlier in this case. In general, NOx emission in zero tilt angle has the lowest sensitivity to excess air. In addition, zero burner angle produces the lowest thermal NOx in the moderate excess air range (excess air between 10\% and $15 \%$ ).

\section{Convective Elements Section}

While tilting burners toward bottom of the furnace leads to an augmentation in the heat absorption of the waterwall, convective section of the boiler (superheaters, reheaters and economizer) will receive a smaller share of the thermal energy produced in the combustion process. This behavior is obvious in Figure 7. In tilt $=+30^{\circ}$ case, for any excess air value, superheaters absorb the highest amount of heat. This is because of the higher furnace exit temperature at positive burner angles. On the other hand, negative tilt angles result in a lower heat transfer to the superheaters.

Decreasing the heat transfer to convective elements of the boiler by reducing burner angle has an exception. At excess air values smaller than $10 \%$, the case with tilt $=-15^{\circ}$ has a lower heat transfer to superheaters than the case with tilt $=-30^{\circ}$. The reason was discussed before for the same behavior observed in Figure 3. Increasing the heat absorption in superheaters by rising the excess air is clearly due to higher mass flow rate over tube banks. Heat transfer to the reheaters and the economizer follows the same pattern. However, heat absorbed by the economizer increases linearly by rising the excess air. 
Looking at Figure 3, the maximum heat transfer to the waterwall achieves in the excess air equal to 5\%. However, by setting the excess air in the range of 0 to $10 \%$, waterwall heat absorption is anyway high and acceptable. Further increasing the excess air leads to lower heat transfer to the waterwall and less steam generation. The situation becomes almost reversed for the convective section (Figure 7). Small amount of excess air ratio results in poor heat transfer to convective elements. Since both sections of the boiler (waterwall and convective section) should be seen together, the efficiency of boiler is a better indicator for evaluating the thermal performance. Boiler efficiency involves all the consequences of changing the tilting angle and excess air, such as: variation in steam production, heat transfer to superheated steam, heat transfer to reheated steam, and water preheating in the economizer.

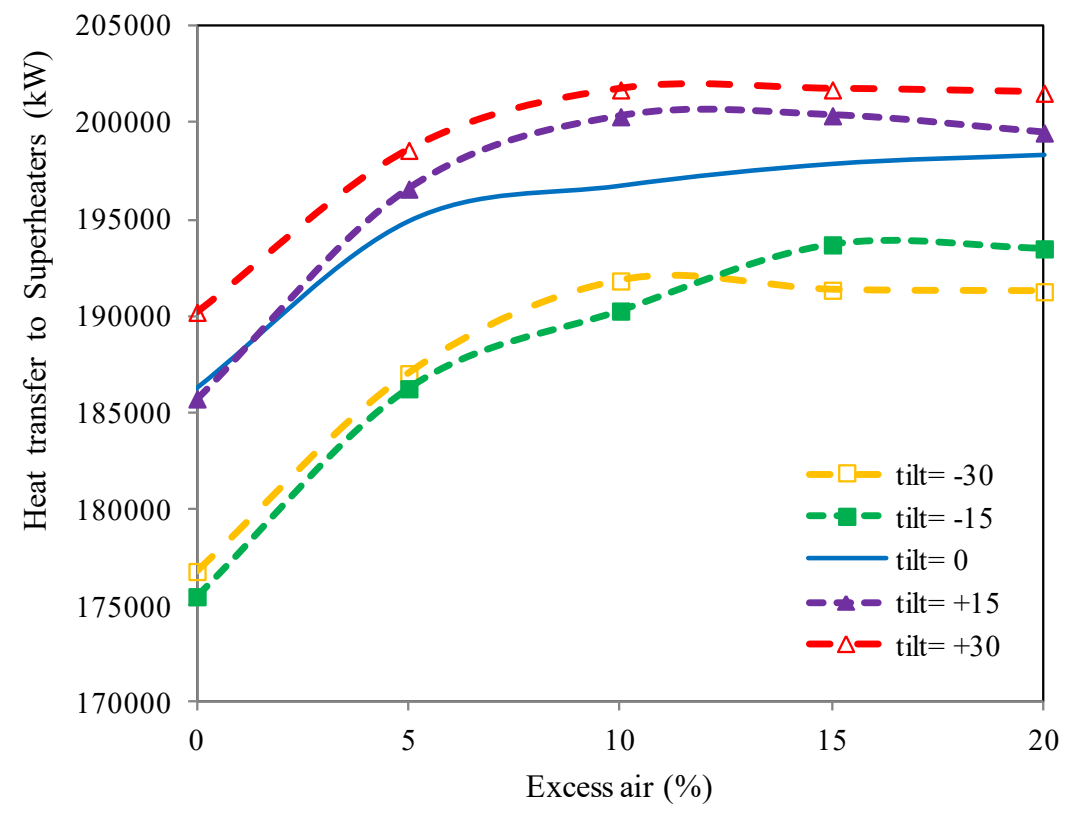

Figure 7. Heat transfer to Superheaters in convective section for various burner angles

As shown in Figure 8, while the excess air is equal to $10 \%$, the boiler efficiency becomes maximum for all tilt angles. The main reason is good heat transfer to the waterwall and the convective section simultaneously when the excess air equals to $10 \%$ (Figure 3 and Figure 7). A boiler efficiency close to $86 \%$ is achievable at negative burner angles with excess air $=10 \%$, which is the optimum thermal performance. In addition, the boiler experiences an unacceptable thermal efficiency with zero excess air value and even with an excess air equal to $20 \%$. When the excess air is $5 \%$ or $15 \%$, the efficiency is somewhat reasonable. In the range from $5 \%$ to $15 \%$, the zero tilting angle case almost has the lowest thermal efficiency. It is worth to mention that the boiler efficiency presented in Figure 8 (and all over this article) is without considering an air preheater. Taking into account this component, the boiler efficiency will increase significantly by utilization of thermal energy of the flue gas leaving the boiler, to heat up the combustion air.

Although the thermal performance of the boiler is a key parameter for choosing the operating variables, two other aspects should be considered, too. The first is $\mathrm{CO}$ and NOx emissions for each operation condition. As discussed earlier, NOx emission increases by rising the excess air value. On the other hand, low excess air values leads to existence of $\mathrm{CO}$ in the stack. Therefore, the optimum choice is an excess air equal to $10 \%$ and the second choice is an excess air equal to $15 \%$. However, if the excess air increases from $10 \%$ to $15 \%$, the NOx emission becomes almost $35 \%$ larger while the $\mathrm{CO}$ emission remains zero. At this range $(10 \%<$ excess air $<15 \%)$, zero tilt angle results in the lowest NOx level, but the efficiency reduces between $1 \%$ and $1.6 \%$ comparing to negative tilt angles. However, for negative burner tilt angles, NOx emission is $1.3 \%$ higher than the zero tilting case. 


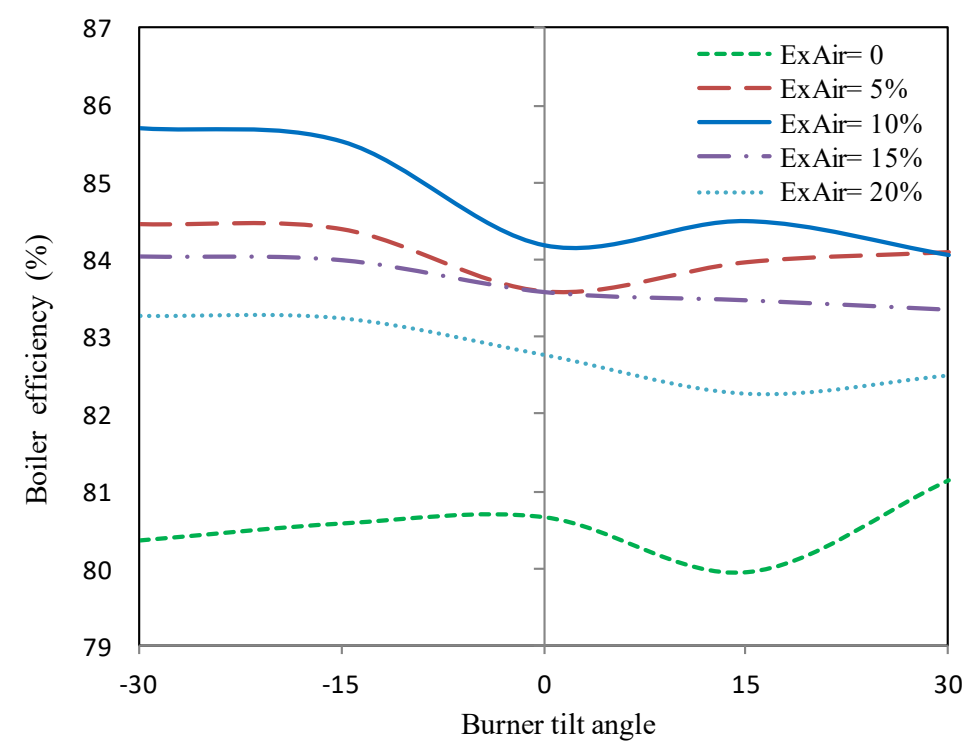

Figure 8. Boiler efficiency for various tilt angles and excess air values

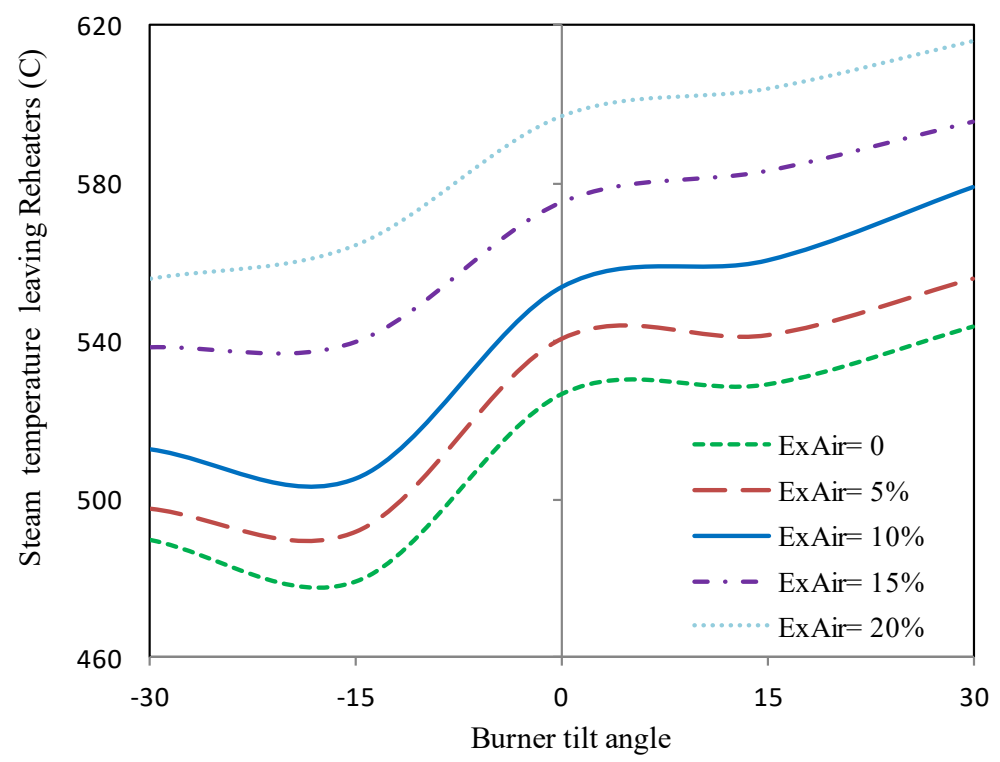

Figure 9. Steam temperature exit from reheaters

The second consideration that should be taken into account is the final superheater/reheater steam temperature. All steam power stations have a set point for the outlet temperature from superheaters and reheaters. The optimum set point, which is achievable by the control system or manual adjustment, is required to meet the desired thermal performance considering metallurgical limitations. The set point for the power plant studied in this article is $538^{\circ} \mathrm{C}$ for both reheater and superheater output. Steam temperature leaving the reheater is illustrated in Figure 9. The same behavior is observable for superheater exit temperature (Figure 10).

In these figures, it is clear that the case with the optimum thermal performance (Figure 8) will not satisfy the steam temperature condition. In fact, the operator should choose an excess air equal to $10 \%$ with zero or positive tilt angle or an excess air equal to $15 \%$ with a negative tilt angle. The first choice results in a boiler efficiency equal to $84.2 \%$ while a little desuperheating water is essential for steam temperature adjustment in reheater and superheater sections. In The second choice, however, the boiler efficiency is almost $84.05 \%$ with no need to desuperheating water. If the excess air value is set to $5 \%$, a zero or positive tilt angle can satisfy the exit temperature threshold. For excess 
air $=5 \%$, using a burner tilt angle equal to 30 is a better option for its higher thermal efficiency $(84.09 \%)$ and lower NOx emission. Nevertheless, as mentioned before, $\mathrm{CO}$ emission is notable for excess air equal to $5 \%$.

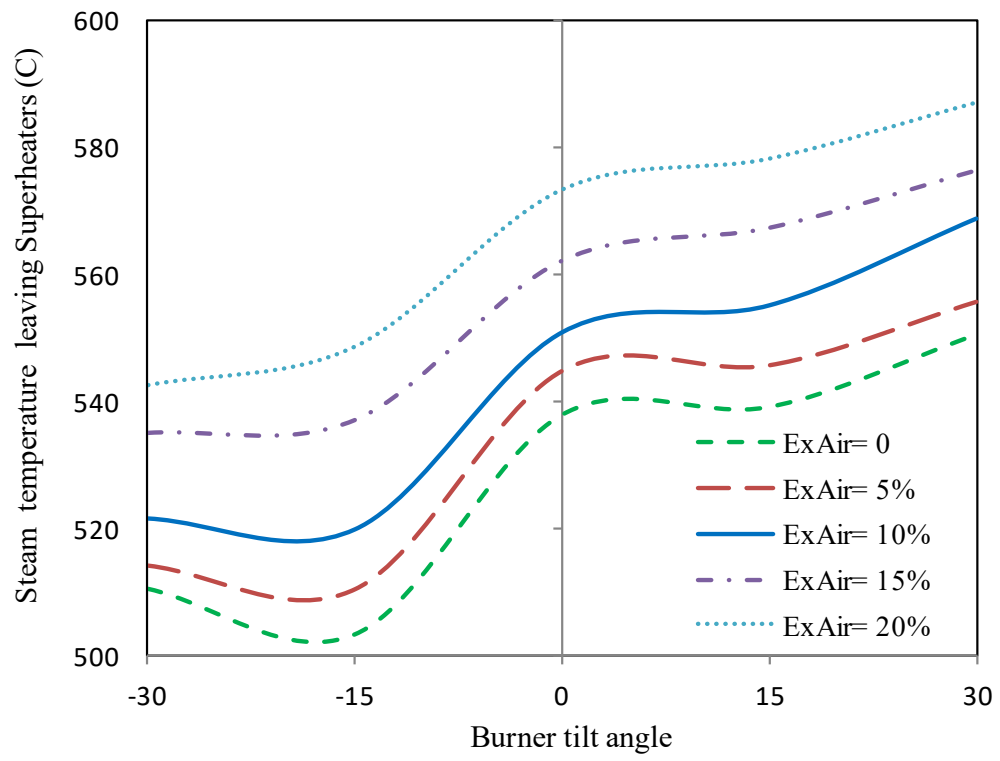

Figure 10. Steam temperature exit from superheaters

For better understanding the results at a glance, the best sets of operating conditions are presented at table 4 . The table is based on the outcomes of convective and furnace sections, as discussed before. All the cases with an efficiency above $83 \%$ are gathered in this table.

Table 4. The consequence of operational parameters and the best sets of these parameters at full load

\begin{tabular}{|l|l|l|l|l|l|l|}
\hline Priority & $\begin{array}{c}\text { Excess air } \\
(\%)\end{array}$ & $\begin{array}{c}\text { Tilt angle } \\
\left({ }^{\circ}\right)\end{array}$ & $\begin{array}{c}\text { Efficiency } \\
(\%)\end{array}$ & CO (ppm) & NOx (ppm) & \multicolumn{1}{|c|}{$\begin{array}{c}\text { Desuperheating } \\
(\text { superheater/reheater })\end{array}$} \\
\hline 1 & 10 & +15 & 84.5 & 0 & 168 & moderate/moderate \\
\hline & & 0 & 84.2 & 6 & 142 & moderate/moderate \\
\hline 2 & 15 & -30 & 84.1 & 0 & 179 & high/high \\
\hline & & -15 & 84 & 0 & 220 & no/no \\
\hline 3 & 10 & -30 & $85.7+$ & 0 & 222 & no/no \\
\hline & & -15 & $85.5+$ & 0 & 160 & no/no+ \\
\hline 4 & 5 & +30 & 84.1 & 550 & 83 & no/no+ \\
\hline & & +15 & 84 & 290 & 114 & moderate/moderate \\
\hline & & 0 & 83.6 & 280 & 125 & low/no \\
\hline 5 & 15 & 0 & 83.6 & 0 & 196 & high/high \\
\hline & & +15 & 83.5 & 0 & 217 & high/high \\
\hline & & +30 & 83.3 & 0 & 191 & high/high \\
\hline 6 & 20 & -30 & 83.3 & 0 & 203 & no/moderate \\
\hline & & -15 & 83.2 & 0 & 208 & low/moderate \\
\hline
\end{tabular}

+ The temperature of main and reheat steam is lower than $538^{\circ} \mathrm{C}$. Thus the efficiency of cycle becomes around $1.5 \%$ lower. This is roughly equivalent to a boiler efficiency of $84.4 \%$ and $84.2 \%$. 


\section{Evaporation Section}

In a utility boiler, metal temperature of the waterwall tubes are very important. These tubes which are exposed to high temperature (flame) may experience tube rupture or overhearing. Boilers are always designed so that the temperature of waterwall tubes never exceeds its metallurgical limitation. However, depending on the operational conditions, boilers may pass over this threshold resulting in rupture in their tubes. Therefore, it is valuable to gain knowledge on the effect of operational conditions on the waterwall tubes temperature.

The temperature of water wall tubes generally depends on the exposed heat flux (radiant and convective), tube outer diameter, tube wall thickness, properties of deposits on inner and outer surface of tubes, and mass flow rate of saturated water flowing inside the tubes. The saturated water flow rate is a function of main steam mass flow rate (steam leaving the drum), circulation ratio of the boiler, inner diameter of tubes, and total number of tubes in the waterwall. Distribution of heat flux on the waterwall surface is obtained from CFD simulation of the furnace. Using the method described in the section 2.4, temperature distribution on the outer surface of the waterwall was computed.

The result for one case is shown in Figure 11. The temperature contours are compared with the total heat flux contours for a wall which has higher local heat flux. As it is obvious, two distributions are almost similar. This is mainly due to the fact that the saturated water flowing inside the tubes has constant temperature in a large portion of the vertical tubes. Thus the distribution of metal tube temperature will be depended only to the heat flux. In the CFD simulations, the waterwall temperature was assumed to be a constant value equal to $750 \mathrm{~K}$. The average temperature of the waterwall can be calculated from Figure 11. In this case, the average surface temperature of the waterwall tubes is equal to $668 \mathrm{~K}$ that is 82 degrees lower than the assumed value in the CFD simulations. Therefore, the radiation heat flux should be higher with this new surface temperature. Repeating the CFD simulation with the new temperature and calculating a newer surface temperature based on new heat flux distribution leads to an iterative computation. After 3 to 4 times of iterations for one case, the final average waterwall temperature became equal to $690 \mathrm{~K}$. In summary, changing the waterwall temperature from $750 \mathrm{~K}$ to $690 \mathrm{~K}$ in the CFD simulation did not change the performance parameters significantly, so the other cases were simulated by CFD without the iteration and with assuming a constant wall temperature $(750 \mathrm{~K})$. For example, total heat absorption by waterwall and exit temperature of the flue gas changed only $0.9 \%$ and $0.2 \%$ by implementing the iteration procedure, respectively.
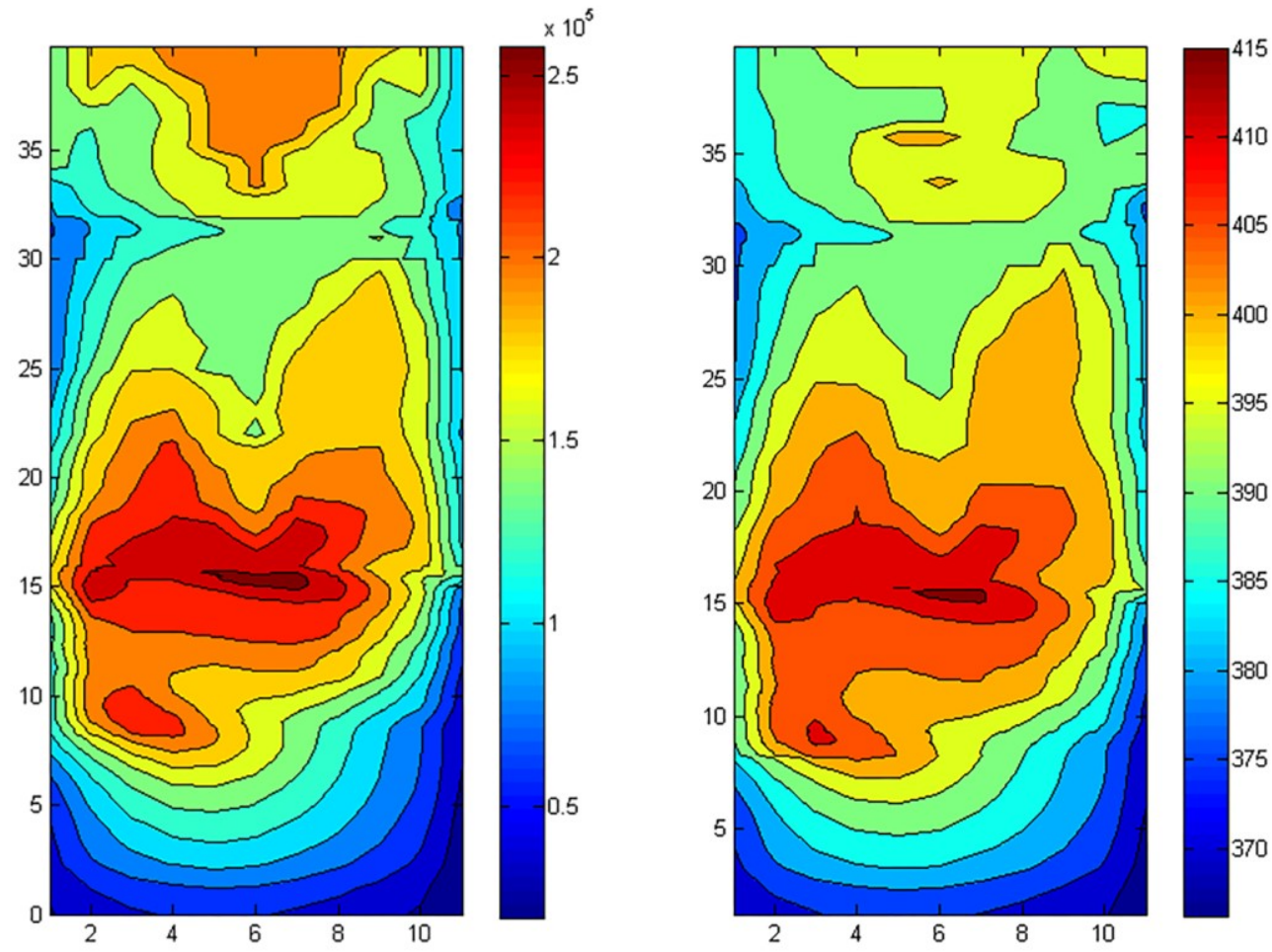

Figure 11. Similarity of contours of the water wall temperature (left) and the heat flux (right) 


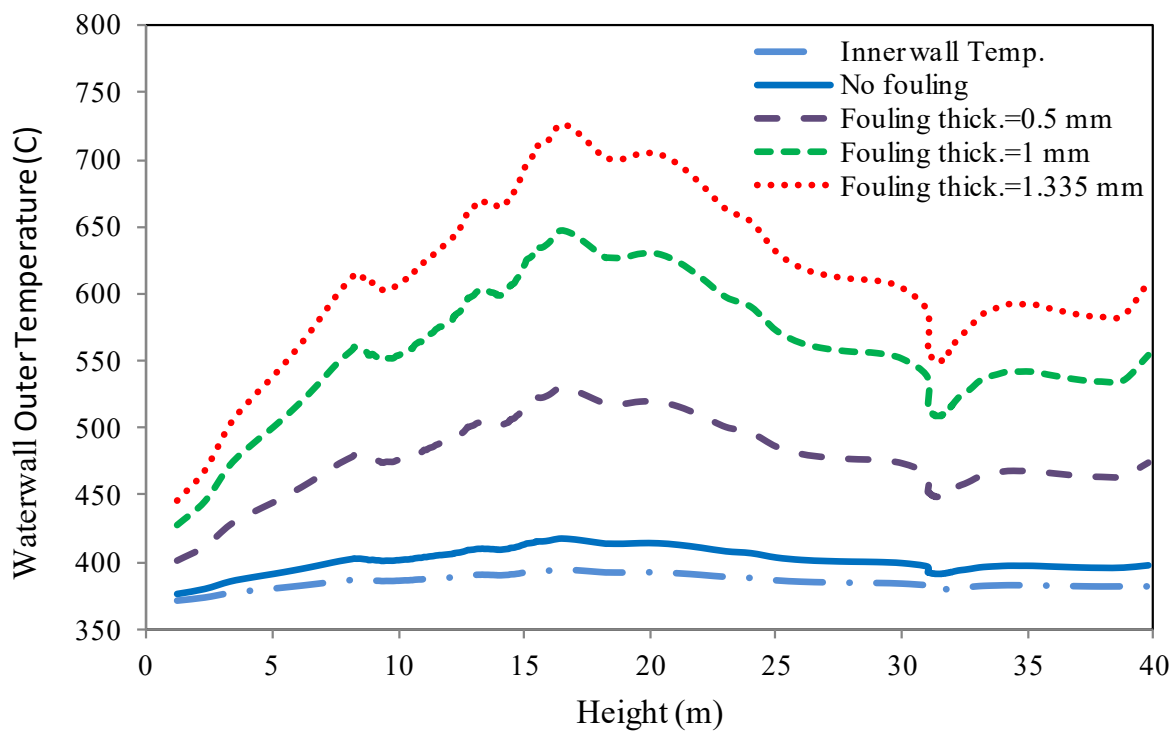

Figure 12. Vertical distribution of the waterwall temperature with various fouling thickness (tilt $=0^{\circ}$, excess air $\left.=10 \%\right)$

Distribution of temperature on the inner and outer surfaces of the waterwall tubes at vertical direction are shown in Figure 12. This figure was plotted for a single vertical tube in the middle of waterwall which had the highest heat flux based on Figure 11. A major point in Figure 12 is how deposits on the inner surface of tubes affect the temperature. A scale layer of $0.5 \mathrm{~mm}$ thickness inside the waterwall tubes has a large influence on maximum metal temperature of the waterwall tubes. This thin layer of fouling formed in the water side increases the maximum temperature by $115{ }^{\circ} \mathrm{C}$. Considering the highest allowable metal temperature equal to $730{ }^{\circ} \mathrm{C}$ [50] which causes a severe short term overheating, the waterwall tubes will be corrupted if the fouling thickness exceeds $1.335 \mathrm{~mm}$ (at tilt $=0^{\circ}$ and ExAir $=10 \%$ ). Thus, metal temperature in the waterwall is strongly depended to the thickness of water side deposition. Although the fouling layer seems to be very thin, it is identical to a fouling resistance of $0.08 \mathrm{~m}^{2} . \mathrm{K} / \mathrm{W}$ that is a huge vale comparing to normal design value $\left(0.0002 \mathrm{~m}^{2} . \mathrm{K} / \mathrm{W}\right)$.

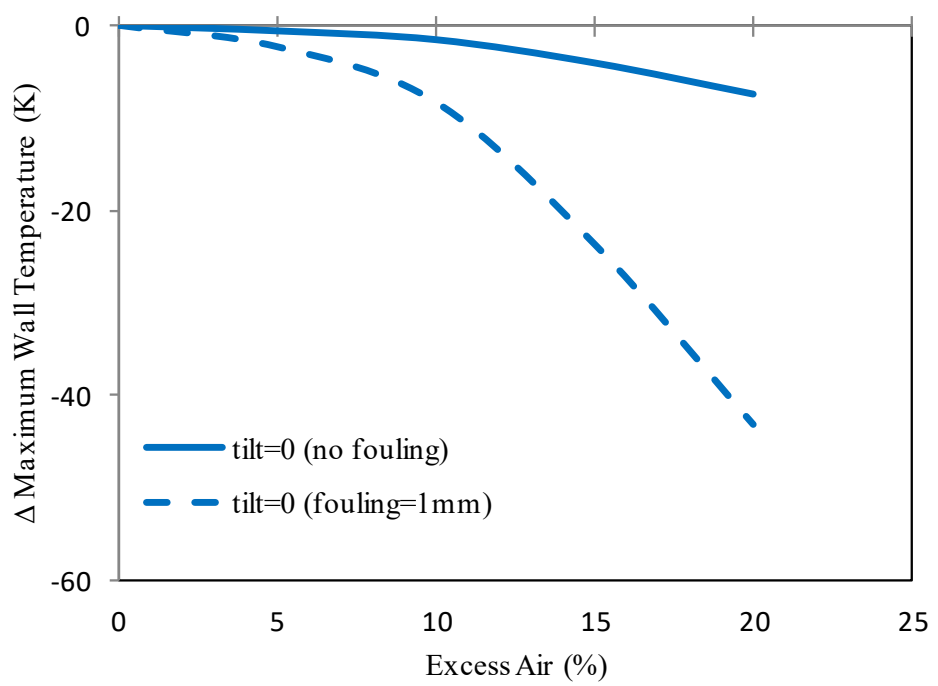

Figure 13. Effect of excess air on the maximum metal temperature in the waterwall tubes (tilt $=0^{\circ}$ )

As shown in Figure 13, the peak metal temperature decreases gradually by increasing the excess air. For tilt angle $=0^{\circ}$ without fouling, the peak temperature drops from $418{ }^{\circ} \mathrm{C}$ to $410{ }^{\circ} \mathrm{C}$ when the excess air goes from $0 \%$ to $20 \%$. By increasing the excess air ratio, as discussed in the previous sections, heat transfer to the waterwall decreases 
while more heat delivers to the economizer. Less heat transfer to the evaporation section of the boiler leads to less water evaporation and hence the water mass flow will be decreased. On the other hand, water will get into the drum with a higher temperature. Consequence of these three changes (higher water temperature, lower water mass flow, and less heat flux) is the reduction of the metal temperature in waterwall.

An important point in Figure 13 is the influence of excess air on the peak temperature while there is fouling inside tubes. Existence of fouling intensifies the so called reduction effect of increasing the excess air value. For the situation of Figure 13, rising the excess air from $0 \%$ to $20 \%$ results in dropping the peak temperature from $654{ }^{\circ} \mathrm{C}$ to $611{ }^{\circ} \mathrm{C}$ which is equal to $43{ }^{\circ} \mathrm{C}$ reduction. This is mainly because of taking into account the reduction of the flow passage of water/steam due to formation of fouling layer. Existence of $1 \mathrm{~mm}$ layer inside a tube with a diameter of $33.9 \mathrm{~mm}$ is equivalent to reducing the flow passage by $6 \%$. As a consequence, the velocity of fluid flow and the internal heat transfer coefficient will be increased. The improvement is relative to the 'no fouling' case. Therefore, peak temperature drops more severely for higher excess air ratios. In other words, the effect of flow passage narrowing for ExAir $=20 \%$ is higher comparing to ExAir $=5 \%$ because the peak temperature differences at 'no fouling' case are $7.3{ }^{\circ} \mathrm{C}$ and $0.6{ }^{\circ} \mathrm{C}$ for excess air of $20 \%$ and $5 \%$ respectively.

This pattern is followed by other tilt angles but there are some exceptions. As it is obvious in Figure 14, reduction effect of the excess air is more sensible at positive tilt angles. The curve related to tilt $=+30^{\circ}$ shows a higher drop in the maximum temperature. The reason is for its lower waterwall heat flux. In addition, the waterwall heat transfer deceases by $12 \%$ moving from a stochastic combustion to $20 \%$ excess air at tilt $=30^{\circ}$. Whereas, this reduction in the heat absorption by the waterwall is less than $8 \%$ in tilt $=0^{\circ}$. Thus, the order of these curves for different tilt angles was expected. However, results of tilt $=-30^{\circ}$ are completely different. Another irregularity in Figure 14 is a growth in the maximum metal temperature at low excess air values for some tilt angles.

Both of this non-uniformities is related to the fact that the maximum metal temperature is not a simple function of waterwall heat transfer, inlet water temperature, and water/steam mass flow. But, the maximum temperature is also dependent to the distribution of the heat flux. In other words, it is possible that in a case with higher total heat transfer (e.g. tilt $=-30^{\circ}$ ), the heat flux becomes excessive in a wide area across waterwall. In contrast, in another case with lower total heat flux, the heat flux becomes more concentrated on a portion of the waterwall. Therefore, supposing a single vertical tube in the high heat flux region, the tube may be exposed to higher heat transfer in the second case.

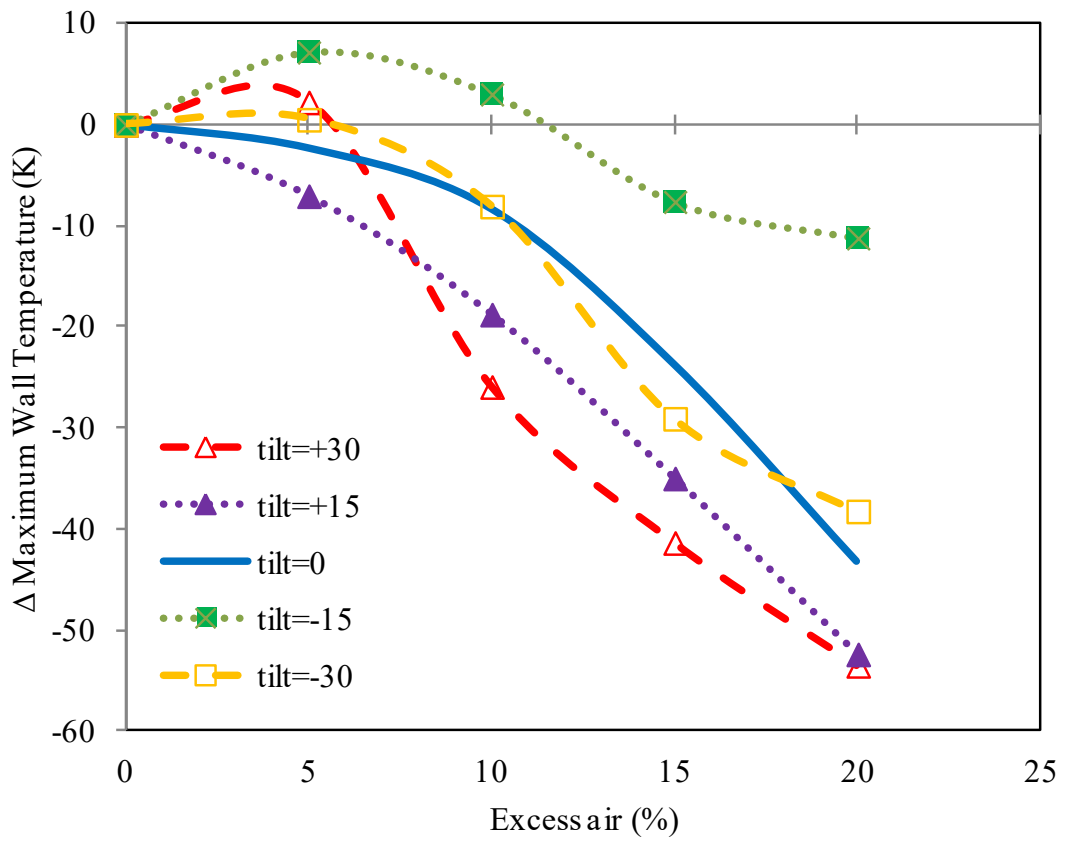

Figure 14. Effect of the excess air and tilt angle on the maximum metal temperature of the waterwall tubes (fouling thickness $=1 \mathrm{~mm}$ ) 
Increasing the thickness of the fouling layer inside tubes over time results in a situation that metal temperature reaches its maximum allowable value $\left(730^{\circ} \mathrm{C}\right)$. This critical fouling thickness is computable for all excess air values and burner tilting angles. As it is illustrated in Figure 15, depending on these two parameters, the critical fouling thickness could be in the range of 1.2-1.55 mm. The zero excess air combustion often leads to lowest critical fouling thickness. An increase in the excess air ratio causes in a larger critical fouling thickness. Similar to Figure 14, only in tilt angles equal to $-30^{\circ},-15^{\circ}$ and $+30^{\circ}$ the critical fouling thickness of $5 \%$ excess air is less than the stoichiometric combustion. Furthermore, the zero tilt angle has the highest critical thickness at low excess air values. When the excess air is higher than $10 \%$, tilt angle equals to zero or $+30^{\circ}$ have the maximum critical thickness.

Figure 15 suggests that in case of high fouling inside the waterwall tubes, it is better to increase the excess air or set the tilt angle to an appropriate value for avoiding tube rupture. In fact, if the fouling is severe especially before boiler tube cleaning, it is recommended to change the excess air and tilt angle to $15 \%$ and $+30^{\circ}$, respectively (keeping in mind table 4). Thus, tube rupture will be avoided by decreasing the boiler efficiency for a small time period prior to tube cleaning. However, it is better to consider the temporary operating values based on the normal operational conditions. For example, if the boiler has been in operation at excess air and tilt angle equals to $5 \%$ and +15 in most of the time, it is sufficient to change the excess air to $10 \%$.

Another issue which is studied in this article is how the circulation ratio of the water/steam circuit affect the overheating risk in the waterwall tubes. The boiler under investigation has a forced circulation system with a ratio equal to 20. It means that a circulation pump circulates the water through the drum and tubes with a mass flow rate 20 times of the mass flow rate of the generated steam. Computations show that increasing the circulation ratio has a minor effect on the maximum metal temperature. If the circulation ratio grows from $20 \%$ to $30 \%$, the maximum tube temperature will be reduced only $0.65 \%$. However, reducing the CR results in a completely different situation.

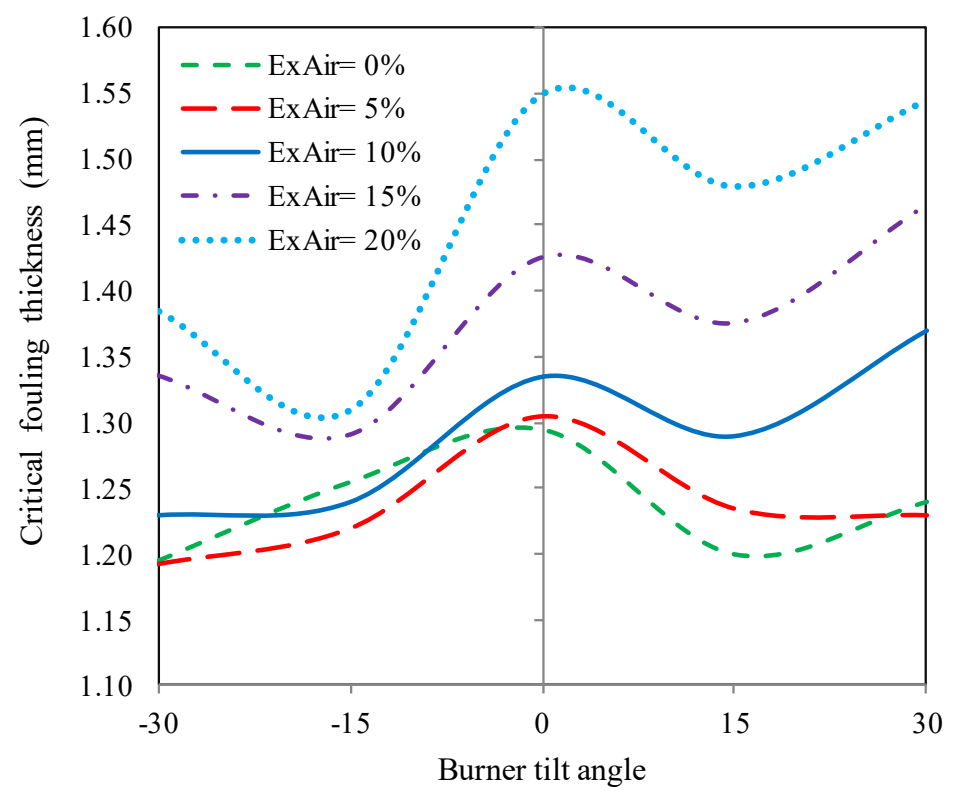

Figure 15. Critical fouling thickness for various tilt angles and excess air values

In normal operation (i.e. circulation ratio $=20$ ) at full load, flow inside all the vertical tubes experience single phase, bubbly flow, slug flow and churn flow patterns. By decreasing the circulation ratio due to a wrong setting or malfunction of valves or the pump, in some tubes which are exposed to highest heat flux, flow would be converted to annular pattern. In all cases, the annular flow will be appeared at a circulation ratio between 17 and 18 . Occurrence of the annular flow pattern is equivalent to possibility of onset of droplet flow and dry-out and hence a sudden jump in metal temperature leading to tube rupture. The exact circulation ratio at which dry-out will be occurred was not calculated because it is a rare situation in a steam power plant boiler. Instead, it is suggested that the operators avoid 
the annular flow pattern conditions to have a better safety margin by carefully monitoring the circulation ratio to keep it away from values lower than 20 .

\section{CONCLUSION}

In this study, three models were integrated to simulate a utility boiler at the full load. These models were a CFD model of the furnace, a mathematical model of the convective elements (i.e. superheaters, reheaters, and economizer), and a mathematical model of the water/steam circuit in the evaporator. The main objective was to find the best operating parameters which lead to the highest possible thermal performance and lowest pollutant emissions while minimize the risk of waterwall tubes overheating. Adjustable parameters in the boiler were excess air and vertical tilting angle of burners. The importance of circulation ratio in the evaporator and the effect of water scale thickness were also discussed.

Some valuable consequences obtained by trusting on the CFD simulations. The present study covers a wider range of the operating parameters comparing to articles mentioned in introduction and explains the possible reasons for the boiler behavior. For example, previous researches claimed that NOx emission is lower at zero tilting angle, whereas the present study showed that such a conclusion is valid only for a moderate excess air value. The main results may be categorized as below:

- Heat transfer to the waterwall increases by inclining the burners downward, whereas the convective elements absorb less thermal energy. Simply it is for shifting the fireball to lower parts of the furnace. One exception is that the burner tilting angle equal to $-15^{\circ}$ transfers more heat to the waterwall comparing to tilt $=-30^{\circ}$, at low excess air values. The reason is that the combustion is more incomplete at tilt $=-30^{\circ}$ in the lower parts of the furnace. Therefore, the gas temperature and radiant heat transfer becomes less than tilt $=-15^{\circ}$. This situation diminishes by increasing the excess air ratio.

- Negative tilting angles result in a growth in the turbulent rate of reaction. This seems to be in contrast with the results represented at [40] where they claimed that the turbulence intensity increases by inclining the burners upward. In the present study it was obtained that the positive titling angles have a higher turbulence comparing to zero burner angle, but the negative burner angles have significantly greater turbulent rate of reaction. Therefore, the result in [40] is not complete because of ignoring the negative burner angles.

- Obviously, $\mathrm{CO}$ is considerable in the excess air values less than $10 \%$. The $\mathrm{CO}$ emission at low excess air values growths by increasing the burner tilt angle.

- NOx emission has a more complex behavior when the tilting angle and excess air ratio changes. At low and high excess air ratios, the positive burner angles result in the lowest level of NOx. In the moderate range of excess air (i.e. values close to $10 \%$ ), the zero tilting angle leads to the minimum NOx emission.

- From the boiler efficiency viewpoint, the negative burner angles are preferred. In addition, an excess air equal to $10 \%$ gives a better thermal performance. Excess air ratios equal to $5 \%$ and $15 \%$ are second and third choices. However, the $10 \%$ excess air with negative burner angles cannot make the superheater/reheater steam temperature to reach their desired values $\left(538{ }^{\circ} \mathrm{C}\right)$. Therefore, the potential of operating conditions in delivering a steam with an appropriate temperature should be considered, too. By considering this issue, negative tilting angles are able to produce the desired steam temperature only with an excess air ratio larger than $15 \%$. Nonetheless, the $10 \%$ excess air with a positive or zero burner angle is much more efficient while it has capable of generating steam of $538^{\circ} \mathrm{C}$. A summary of the best operating choices by considering the boiler efficiency, $\mathrm{CO}$ and $\mathrm{NOx}$ emissions, and final steam temperatures was demonstrated in table 4.

- Thickness of the scale formed inside the waterwall tubes has a significant influence on the metal temperature and risk of tube rupture. Negative effect of fouling on the metal temperature was found to be depended on the excess air values. Increasing the excess air leads to a reduction in metal tube temperature. A similar pattern was observed for all tilt angles with some quantitative differences because of the different values of heat transfer to the waterwall.

- A critical fouling thickness was defined in which the metal temperature exceeds the short term overheating threshold $\left(730^{\circ} \mathrm{C}\right)$. The critical thickness for various cases obtained between $1.2-1.55 \mathrm{~mm}$. Obviously, 
increasing the excess air leads to a higher critical fouling thickness. This means that if the fouling thickness is near critical values, it is better to temporarily increase the excess air until the boiler be shut down for tubes cleaning. Zero and $+30^{\circ}$ tilt angles also have the same effect. In other words, setting the burner tilt angle to one of these two values results in a safer operation if the fouling thickness is high.

- Decreasing the circulation ratio may change the flow pattern inside vertical tubes of the waterwall. Almost in all cases, a $C R$ equal to $17-18$ can lead the boiler to a dry-out and rupture situation.

\begin{tabular}{|c|c|}
\hline \multicolumn{2}{|c|}{ NOMENCLATURE } \\
\hline Bo & Boiling number \\
\hline$C$ & Constant in Grismon equation (1) \\
\hline$C R$ & Circulation ratio of boiler \\
\hline$D_{e q}$ & Equivalent inner diameter of tube considering fouling thickness $(\mathrm{m})$ \\
\hline$D_{i}$ & Tube inner diameter \\
\hline E & Enhancement factor \\
\hline$f$ & Friction factor \\
\hline$G$ & Mass flux $\left(\mathrm{Kg} \mathrm{m}^{-2} \mathrm{~s}^{-1}\right)$ \\
\hline$k_{l}$ & Thermal conductivity of saturated liquid $\left(\mathrm{W} \mathrm{m}^{-1} \mathrm{~K}^{-1}\right)$ \\
\hline$\dot{M}_{I P T}$ & Mass flow rate at IPT inlet $\left(\mathrm{kg} \mathrm{s}^{-1}\right)$ \\
\hline$\dot{M}_{\text {steam }}$ & Mass flow rate of steam inside tubes of waterwall $\left(\mathrm{Kg} \mathrm{s}^{-1}\right)$ \\
\hline$M W$ & Molecular weight of water $\left(18.015 \mathrm{Kmol} \mathrm{Kg}^{-1}\right)$ \\
\hline$n$ & Constant in Grismon equation (1) \\
\hline$N u_{\text {in }}$ & Nusselt number for internal flow in tubes \\
\hline$N u_{e x}$ & Nusselt number for external flow over tube banks \\
\hline$N_{\text {tube }}$ & Number of tubes in water wall \\
\hline$P$ & static pressure (bar) \\
\hline$P_{c r}$ & critical pressure (bar) \\
\hline$P_{I P T}$ & Pressure at IPT inlet (pa) \\
\hline$P r_{g a s}$ & Flue gas Prandtl number \\
\hline $\mathrm{Pr}_{l}$ & Prandtl number for saturated liquid \\
\hline Prst & Superheated steam Prandtl number \\
\hline$q_{\text {tube }}$ & Heat flux to a single tube $\left(\mathrm{W} \mathrm{m}^{-2}\right)$ \\
\hline$R e_{\text {in }}$ & Reynolds number for internal flow in tubes \\
\hline $\operatorname{Re}_{l}$ & Reynolds number for flow of saturated liquid \\
\hline $\operatorname{Re}_{\max }$ & Maximum Reynolds number of gas flowing over tube banks \\
\hline$S$ & Suppression factor \\
\hline$T_{\text {sat. }}$ & Water saturation temperature $(\mathrm{C})$ \\
\hline$T_{w}$ & Tube wall temperature $(\mathrm{C})$ \\
\hline$T_{w}$ ONB & Temperature of onset of nucleate boiling (C) \\
\hline$u_{l}$ & Liquid velocity in two phase flow $\left(\mathrm{kg} \mathrm{m}^{-1}\right)$ \\
\hline$x$ & Vapor quality \\
\hline$x_{A F}$ & Vapor quality of appearing the annular flow \\
\hline$X_{t t}$ & Martinelli parameter \\
\hline$\alpha_{c o n v}$ & Convective heat transfer $\left(\mathrm{W} \mathrm{m}^{-2} \mathrm{~K}^{-1}\right)$ \\
\hline$\alpha_{n b}$ & Saturated nucleate boiling heat transfer $\left(\mathrm{W} \mathrm{m}^{-2} \mathrm{~K}^{-1}\right)$ \\
\hline$\alpha_{\text {pool }}$ & Pool boiling heat transfer $\left(\mathrm{W} \mathrm{m}^{-2} \mathrm{~K}^{-1}\right)$ \\
\hline$\rho_{I P T}$ & Density of steam at IPT inlet $\left(\mathrm{Kg} \mathrm{m}^{-3}\right)$ \\
\hline$\varphi$ & Mass flow coefficient of intermediate pressure turbine (IPT) \\
\hline
\end{tabular}




\section{REFERENCES}

[1] Hasini H, Yusoff MZ, Shuaib NH, Boosroh MH, Haniff MA. Analysis of flow and temperature distribution in a full scale utility boiler using CFD. In 2009 3rd International Conference on Energy and Environment (ICEE) 2009 Dec 7 (pp. 208-214). IEEE, http://dx.doi.org/10.1109/ICEENVIRON.2009.5398646.

[2] Park JK, Park S, Ryu C, Baek SH, Kim YJ, Park HY. CFD analysis on bioliquid co-firing with heavy fuel oil in a 400 MWe power plant with a wall-firing boiler. Applied Thermal Engineering. 2017;124:1247-56, http://dx.doi.org/10.1016/j.applthermaleng.2017.06.104.

[3] Galindo-Garci'a IF, Va'zquez Barraga'n AK, Rossano Roma'n M. Numerical study of the flow and temperature distributions in a $350 \mathrm{mw}$ utility boiler. In ASME Power Conference 2010. (49354) p. 767-775.

[4] Masoumi H, Abroshan H. Numerical investigation of burner angles effect on the combustion phenomenon in a selected power plant boiler. Fuel and Combustion Journal. 2012; 1:1-13.

[5] Du Y, Lv Q, Li D, Liu H, Che D. CFD investigation on combustion and NOx emission characteristics in a 600 MW wall-fired boiler under high temperature and strong reducing atmosphere. Applied Thermal Engineering. 2017; 126:407-18.

[6] Arablu M, Poursaeidi E. Using CFD for NO x emission simulation in a dual fuel boiler. Combustion, Explosion, and Shock Waves. 2011;47(4):426.

[7] Hochenauer C, Brandstetter G. CFD simulation of a low NOx oil fired boiler. In Turbo Expo: Power for Land, Sea, and Air 2005;4725:1-10.

[8] Yue-yun S, Xiao-tao G, Ming-yao Z. Numerical study on the impact of varying operation conditions on nox emissions of large-scale pulverized coal-fired utility boiler. In International Symposium on Coal Combustion Berlin, Heidelberg, Germany. Springer; 2011. p. 1141-1152.

[9] Luan S, Ma Z, Wang H, Zhang Y, Lu P. CFD modeling and field testing of a 600-MW wall-fired boiler burning low-volatile bituminous coal. International Symposium on Coal Combustion, Singapore. Springer; 2015. p.213-219.

[10] Gao H, Runstedtler A, Majeski A, Boisvert P, Campbell D. Optimizing a woodchip and coal co-firing retrofit for a power utility boiler using CFD. Biomass and Bioenergy. 2016; 88:35-42.

[11] Rahimi M, Khoshhal A, Shariati SM. CFD modeling of a boiler's tubes rupture. Applied Thermal Engineering. 2006;26(17-18):2192-2200.

[12] Tang G, Wu B, Johnson K, Kirk A, Zhou CQ. Simulation of an industrial tangentially fired boiler firing metallurgical gases. Journal of Thermal Science and Engineering Applications [Internet]. 2014;7(1): (011003) 1-11. Available from: https://doi.org/10.1115/1.4028344.

[13] Purimetla A, Cui J. CFD studies on burner secondary airflow. Applied Mathematical Modelling. 2009;33(2):1126-40.

[14] Vuthaluru HB, Vuthaluru R. Control of ash related problems in a large scale tangentially fired boiler using CFD modelling. Applied Energy. 2010;87(4):1418-26.

[15] Schuhbauer C, Angerer M, Spliethoff H, Kluger F, Tschaffon H. Coupled simulation of a tangentially hard coal fired $700^{\circ} \mathrm{C}$ boiler. Fuel. 2014;122:149-63, http://dx.doi.org/10.1016/j.fuel.2014.01.032.

[16] Drosatos P, Nikolopoulos N, Agraniotis M, Itskos G, Grammelis P, Kakaras E. Decoupled CFD simulation of furnace and heat exchangers in a lignite utility boiler. Fuel. 2014;117:633-48, http://dx.doi.org/10.1016/j.fuel.2013.09.033.

[17] Bar-Ziv E, Berman Y, Saveliev R, Perelman M, Korytnyi E, Davidson B, Chudnovsky B. Fouling formation in $575 \mathrm{mv}$ tangential-fired pulverized-coal boiler. Journal of Engineering for Gas Turbines and Power [Internet]. 2010;132(12):(123001) 1-7. Available from: https://doi.org/10.1115/1.4001297.

[18] Taha TJ, Stam AF, Stam K, Brem G. CFD modeling of ash deposition for co-combustion of MBM with coal in a tangentially fired utility boiler. Fuel Processing Technology. 2013; 114:126-34.

[19] Cantrell C, Idem S. On-line performance model of the convection passes of a pulverized coal boiler. Heat Transfer Engineering. 2010;31(14):1173-83.

[20] Bhambare KS, Mitra SK, Gaitonde UN. Modeling of a coal-fired natural circulation boiler. Journal of Energy Resources Technology. 2007;129(2):159-167. 
[21] Sreepradha C, Panda RC, Bhuvaneswari NS. Mathematical model for integrated coal fired thermal boiler using physical laws. Energy. 2017; 118:985-98.

[22] Chaibakhsh A, Ghaffari A, Moosavian SA. A simulated model for a once-through boiler by parameter adjustment based on genetic algorithms. Simulation Modelling Practice and Theory. 2007;15(9):1029-51, http://dx.doi.org/10.1016/j.simpat.2007.06.004.

[23] Zhang W, Wang H, Yan K, Zhou T, Wang CA, Chen K, Che D. Mathematical modeling and thermalhydrodynamic analysis of vertical water wall in a SCFB boiler with annular furnace. Applied Thermal Engineering. 2016; 102:742-8.

[24] Zima W, Nowak-Ocłoń M, Ocłoń P. Simulation of fluid heating in combustion chamber waterwalls of boilers for supercritical steam parameters. Energy. 2015; 92:117-27.

[25] Kim S, Choi S. Dynamic simulation of the water-steam flow in a supercritical once-through boiler. Journal of Mechanical Science and Technology. 2017;31(10):4965-75, http://dx.doi.org/10.1007/s12206-017-0945-z.

[26] Zima W. Mathematical Modelling of Dynamics of Boiler Surfaces Heated Convectively. In: Vikhrenko VS. (ed.). Heat Transfer-Engineering Applications [Internet]. Rijeka: IntechOpen; 2011. Available from: https://doi.org/10.5772/26231, p. 259-282.

[27] Singer JG. Combustion - Fossil Power Systems - a Reference Book on Fuel Burning and Steam Generation, Combustion Engineering. Inc., Windsor, CT; 1981.

[28] Munisamy KM, Yusoff MZ, Thangaraju SK, Hassan H, Ahmad A. Burner tilting angle effect on velocity profile in 700 MW Utility Boiler. IOP Conference Series: Materials Science and Engineering. 2015 Sep; 88:012021.

[29] Kumar M, Sahu SG. Study on the effect of the operating condition on a pulverized coal-fired furnace using computational fluid dynamics commercial code. Energy \& Fuels. 2007;21(6):3189-93.

[30] Tree DR, Webb BW. Local temperature measurements in a full-scale utility boiler with overfire air. Fuel. 1997;76(11):1057-66.

[31] Hill SC, Smoot LD. Modeling of nitrogen oxides formation and destruction in combustion systems. Progress in Energy and Combustion Science. 2000;26(4-6):417-58.

[32] Hao Z, Kefa C, Ping S. Prediction of ash deposition in ash hopper when tilting burners are used. Fuel Processing Technology. 2002;79(2):181-95.

[33] Dal Secco S, Juan O, Louis-Louisy M, Lucas JY, Plion P, Porcheron L. Using a genetic algorithm and CFD to identify low NOx configurations in an industrial boiler. Fuel. 2015; 158:672-83.

[34] Tian D, Zhong L, Tan P, Ma L, Fang Q, Zhang C, Zhang D, Chen G. Influence of vertical burner tilt angle on the gas temperature deviation in a $700 \mathrm{MW}$ low NOx tangentially fired pulverised-coal boiler. Fuel Processing Technology. 2015; 138:616-28.

[35] Tan P, Tian D, Fang Q, Ma L, Zhang C, Chen G, Zhong L, Zhang H. Effects of burner tilt angle on the combustion and NOx emission characteristics of a 700 MWe deep-air-staged tangentially pulverized-coalfired boiler. Fuel. 2017;196:314-24, http://dx.doi.org/10.1016/j.fuel.2017.02.009.

[36] Więckowski $Ł$, Krawczyk P, Badyda K. Numerical investigation of temperature distribution in the furnace of a coal fired grate boiler in part load conditions. Journal of Power Technologies. 2018;97(5):359-65.

[37] Al-Mawali J, Dakka SM. Numerical analysis of flame characteristics and stability for conical nozzle burner. Journal of Thermal Engineering. 2019;5(5): 422-445, http://dx.doi.org/10.18186/thermal.624070.

[38] Marias F, Puiggali JR, Quintard M, Pit F. Quality of CFD models for jet flow analysis for the design of burners and boilers. Korean Journal of Chemical Engineering. 2002;19(1):28, http://dx.doi.org/10.1007/BF02706871

[39] Holman JP. Heat Transfer, Eighth SI Metric Edition. Mc Gran-Hill Book Company. 2001.

[40] Kays WM, Lo RK. Basic heat transfer and flow friction design data for gas flow to banks of staggered tubes: use of a transient technique. Technical Report 15. Stanford University.; 1952 Aug 15.

[41] Petukhov BS. Heat transfer and friction in turbulent pipe flow with variable physical properties. Advances in Heat Transfer. 1970; 6:503-564.

[42] Cooke DH. On prediction of off-design multistage turbine pressures by stodola's ellipse. Journal of Engineering for Gas Turbines and Power. 1985;107(3):596-606, http://dx.doi.org/10.1115/1.3239778 
[43] Collier JG, Thome JR. Convective Boiling and Condensation. Clarendon Press; 1994.

[44] Bergles AE, Rohsenow WM. The determination of forced-convection surface-boiling heat transfer. Journal of Heat Transfer. 1964;86(3): 365-372.

[45] Petelin, S, Koncar, B. Prediction of void fraction in subcooled flow boiling. International Conference in Nuclear Energy in Central Europe, Slovenia. 1998:195-222.

[46] Gungor KE, Winterton RH. A general correlation for flow boiling in tubes and annuli. International Journal of Heat and Mass Transfer. 1986;29(3):351-8, http://dx.doi.org/10.1016/0017-9310(86)90205-X.

[47] Chen JC. Correlation for boiling heat transfer to saturated fluids in convective flow. Industrial \& Engineering Chemistry Process Design and Development. 1966;5(3):322-9.

[48] Cooper MG. Saturation nucleate pool boiling - a simple correlation. First UK National Conference on Heat Transfer [Internet]. Elsevier; 1984. p. 785-93. Available from: http://dx.doi.org/10.1016/B978-0-85295-1750.50013-8.

[49] Jiao B, Qiu LM, Lu JL, Gan ZH. Liquid film dryout model for predicting critical heat flux in annular twophase flow. Journal of Zhejiang University-Science A. 2009;10(3):398-417, http://dx.doi.org/10.1631/jzus.A0820322.

[50] Port RD, Herro HM. The Nalco Guide to Boiler Failure Analysis: The Nalco Chemical. McGraw-Hill; 1991. 